Estudios Constitucionales, Año 15, № 2, 2017, pp. 389-446

ISSN 07180105

Centro de Estudios Constitucionales de Chile Universidad de Talca

"Control institucional de decisiones legislativas político-criminales"

Javier Wilenmann von Bernath

\title{
CONTROL INSTITUCIONAL DE DECISIONES LEGISLATIVAS POLÍTICO-CRIMINALES
}

\section{INSTITUTIONAL CONTROL OF LEGISLATIVE CRIMINAL LAW DECISIONS}

\author{
JaVier WilenManN VON BERNATH* \\ Universidad Adolfo Ibáñez \\ javier.wilemann@uai.cl
}

RESUMEN: El artículo presenta una critica a los discursos de control sustantivo de la legislación penal. Éste muestra cómo los discursos elaborados desde el ámbito de estudio del derecho penal sufren de falta de fundamentos, mientras que el control de leyes penales bajo utilización de aparatos de la dogmática constitucional se ha mostrado ineficaz para hacer frente a las patologías de la politica criminal. En vez de centrarse en el control judicial, el artículo sugiere un acercamiento propiamente político en la solución de los problemas políticos que se encuentran en el origen de las tendencias en cuestión.

PALABRAS CLAVE: Criminalización, derecho constitucional y sistema penal, teoría constitucional, politica criminal, control constitucional.

ABSTRACT: The paper criticizes existing discourses regarding the control of criminal law. It aims at demonstrating that the critical discourses developed by scholars of criminal law show lack of institutional foundations, while judicial review of substantive criminal law has proved itself ineffective to contribute to the rationalization of criminal law politics. The paper suggests that, instead on focusing on the discussion around judicial review standards, the concern with criminal legislation should lead to an institutional, political process-oriented approach to the political pathologies at the source of scholar's concerns.

KEYWORDS: Criminalization, constitutional law and criminal law system, constitutional theory, criminal politics, judicial review.

\footnotetext{
* Profesor Asociado Facultad de Derecho Universidad Adolfo Ibáńez. Este artículo ha sido desarrollado como parte del proyecto Fondecyt No 1170056, sobre "La conformación del derecho penal entre política y cultura", del cual el autor es investigador responsable. Le agradezco asimismo a la Alexander von Humboldt Stiftung por otorgarme la beca que hizo posible el inicio de la realización de esta investigación. Parte importante de la investigación tuvo lugar en el Institut für Strafrecht und Rechtsphilosophie de la Universidad de Freiburg, dirigido por el profesor Michael Pawlik, a quien agradezco por su generosa recepción y disposición a discutir sobre varios de los temas tratados en este artículo. Agradezco asimismo a los funcionarios del Institut für Staatsrecht und Staatsphilosophie, dirigido por el profesor Andreas Voßkuhle, y en especial a Thomas Wischmeyer, por facilitarme el uso de sus instalaciones y el acceso a la literatura contenida en la biblioteca más allá de los horarios de apertura al público.
} 


\section{INTRODUCCIÓN}

En este artículo nos interesa analizar la capacidad de rendimiento de las distintas clases de discursos construidos por las ciencias jurídicas para controlar el output de la política legislativa penal y, ante todo, en relación a decisiones de criminalización ${ }^{1}$. En particular, nos interesa analizar la plausibilidad de los discursos de control institucional típicamente reconocibles en la dogmática penal y en la dogmática y práctica constitucional.

La tesis del artículo es, a grandes rasgos, sencilla: los discursos de control que tienden a manejarse son, por distintas razones, problemáticos. Los discursos construidos por la dogmática penal sufren de imprecisión, mientras que los discursos constitucionales, construidos sobre el paradigma del control judicial, tienden a ser ineficaces en relación con sus propias pretensiones.

Así, en el primer caso, a causa de su propia estructura disciplinaria basada en una autodefinición sustantiva - "la dogmática penal debe construirse con base en una especial preocupación por aquello que justifica moralmente la existencia de la pena estatal"-, las ciencias jurídicas penales tienden a construir discursos sustantivos de control bajo la asunción (en general implícita) de que ellos deben expresarse en alguna clase de control judicial sustantivo. Sus dos premisas centrales pueden así denominarse definición disciplinaria sustantiva y continuidad entre esa definición metodológica y los discursos sobre mecanismos de control que se realizan en el control judicial ("tesis de la continuidad") 2 . Como veremos, ninguna de esas premisas resulta convincente, al punto de que, en la práctica comparada, ellos no tienden a tener reconocimiento institucional. Éste ya no es, desafortunadamente, el caso en Chile: desde al menos el año 2017 es posible verificar una tendencia de la práctica constitucional chilena a razonar de un modo

\footnotetext{
${ }^{1}$ Esto no quiere decir sólo controlar la política criminal, porque política criminal implica asumir que se trata del control de decisiones que pueden convertirse en derecho, pero que todavía no lo son. Éste es ciertamente el caso de los controles preventivos de constitucionalidad -y ante todo de mecanismos de conducción de la política misma-, pero no así de los controles represivos. La práctica penal muestra, sin embargo, que el control tiende a jugarse respecto de normas vigentes: las decisiones de control de legitimidad de la prohibición y punición de la sodomía consentida entre adultos o con adolescentes, del incesto o del aborto consentido por la mujer se refieren, en general, a normas asumidas como válidas. Por eso, es preferible usar el concepto de "decisiones de criminalización".

2 En este aspecto, el artículo forma parte de una serie de tres artículos que busca criticar la capacidad de rendimiento de la práctica de argumentación en torno a "los fines de la pena" en tres ámbitos distintos: en la discusión sobre la justificación política del derecho penal; en la discusión sobre el razonamiento dogmáticopenal, y, aquí, en el control de la política legislativa penal.
} 
influido por la dogmática penal ${ }^{3}$. A causa de lo anterior, la crítica al modo de razonamiento que uno puede denominar "sustantivo-penal" en la construcción de estándares institucionales de control de la legislación penal es especialmente relevante en Chile.

Los discursos construidos por la dogmática constitucional tienen diferencias estructurales relevantes -ante todo, el control constitucional es parte del objeto de interés directamente dogmático de la doctrina constitucional- y tienen un mayor grado de precisión conceptual en la satisfacción de lo que caracteriza a los mecanismos de control, pero sufren en cualquier caso de falta de eficacia. Antes que discursos de control con pretensiones institucionales, el interés por la racionalidad de la práctica punitiva parece necesitar de preocupación por los modos de organización de la política que tiendan a la resolución de los problemas específicos que ella plantea en el ámbito criminal. Como veremos, ello es visible con particular claridad en el ámbito de las decisiones de criminalización (o su contrario: de-criminalización) de conductas determinadas: el carácter abiertamente político conflicto de las discusiones sobre criminalización implica que la pretensión de controlar el output de la legislación por pura evaluación neutra de su legitimidad sea especialmente improbable (al extremo: imposible) de satisfacer.

Siguiendo la estructura del argumento, el artículo se divide en cuatro partes. La primera parte del artículo (I) tiene por objeto especificar qué es, para nuestros efectos, un discurso teórico-jurídico con pretensiones críticas o de control, esto es, precisar el objeto de análisis. Más allá del interés de la pregunta en sí, ella tiene relevancia tanto porque permite entender de inmediato las deficiencias que suponen las ambigüedades de la idea de "pretensión crítica" en los discursos construidos por las ciencias penales ${ }^{4}$, cuanto como porque permite al mismo tiempo observar con precisión las diferencias conceptuales entre los discursos críticos elaborados por las ciencias jurídicas y el análisis de los mecanismos de control de la dogmática constitucional.

La sección II reconstruye los rasgos centrales de los mecanismos de control ofrecidos por la literatura y, al menos en lo referido a los discursos construidos por la dogmática penal, los somete a crítica. Como veremos, pese a que todos los discursos especifiquen (o debieran especificar) condiciones de éxito del control

3 Véase la sección II.4.

4 Crítico respecto a la ambigüedad con relación al significado de la idea de pretensión crítica en la teoría del bien jurídico recientemente GärDITZ (2017), p. 642 y s. 
judicial (preventivo o represivo) de leyes penales, los discursos elaborados por las ciencias penales se caracterizan por postular una continuidad entre el discurso explicativo legitimatorio inicial ("la teoría de la pena") y el discurso crítico. En el caso de la dogmática constitucional, esa diferencia desaparece, ya que la pretensión crítica puede serle imputada directamente a la práctica que se reconstruye (el derecho constitucional). Ello explica que los discursos constitucionales se encuentren en mejor posición de fundamentación del rendimiento institucional del discurso -eso es obvio- y tengan mayor precisión en el cumplimiento de lo que se espera (o debiera esperarse) de un discurso crítico. Pese a ello, la clase de acciones a las que la dogmática constitucional pretende prestarle atención la llevan a la asunción de rasgos compartidos con los discursos provenientes de la literatura penal -su orientación al control sustantivo-. Los discursos constitucionales no son, así, generalmente (esto es: salvo en casos patológicos) criticables por su compatibilidad con el contenido o con la práctica del derecho y constituyen, por ello, el mejor caso para analizar el potencial de rendimiento general del control judicial sustantivo en lo relativo al contenido de la política criminal.

La sección III trabaja sobre esta asunción: asumido que sea que los discursos constitucionales de control se encuentran en mejor posición para tender al tipo de control al que pretenden sujetar a la legislación penal, la sección III critica su capacidad de rendimiento. Para ello, la sección III abre con una crítica general a la tendencia de la política criminal contemporánea a asumir características irracionales y muestra que el control judicial no sólo no ha tenido efectos en contrarrestar esto, sino que incluso parece haber coadyuvado a su desarrollo. Centrándose en el caso paradigmáticamente conflictivo de las decisiones legislativas de criminalización, la sección III ensaya una explicación: los mecanismos de control que siguen una lógica judicial tienden a no tener rendimiento en el encauzamiento de la política cuando ella es, entre otras cosas, abiertamente conflictiva. Por supuesto, el argumento podría ser expuesto con carácter general: también en discusiones sobre graduación de la pena o política de ejecución de la pena (¡y, por cierto, también fuera del derecho penal!) influyen factores políticos difícilmente apreciables con los esquemas tradicionales. El ámbito de la criminalización ofrece, sin embargo, una claridad que en los demás casos puede ser opacada: las discusiones sobre graduación, determinación y ejecución de la pena pueden ser entendidas como discusiones "técnicas" que se dejan evaluar en su mérito y justicia sustantiva de modo neutro - hay tal vez algo ingenuo en pensar la cuestión así, como si las motivaciones políticas subjetivamente atribuibles a los actores con representación y objetivamente atribuibles al sistema en general fueran sólo de esta clase, pero 
ése es en todo caso el modo en que plantean la cuestión-. En cambio, como veremos, en el ámbito de la criminalización, su planteamiento como un problema de justicia sustantiva neutro es radicalmente incompatible con la realidad política de la cuestión.

La sección IV sugiere, por ello, un cambio de enfoque. Si la preocupación es la racionalización de la política criminal (incluyendo la política de revisión del derecho vigente), entonces, la tendencia a centrarse en el control judicial que deriva de la identidad misma de la dogmática se muestra como un mal aliado. Ello no quiere decir, sin embargo, que debamos simplemente conformarnos con las tendencias irracionales de la política criminal; si el problema se encuentra en su output, pero el derecho no puede controlar eficazmente ese output, éste (y en particular el derecho constitucional) sí puede reflexionar sobre las condiciones de producción de ese output de modo tal de hacer frente a las patologías que explican sus déficits de resultados.

\section{Pretensión teórica reconstructiva y pretensión teórica critica}

Nos interesa, como hemos visto, analizar las posibilidades de control institucional del output de la política criminal. Pese a que esa preocupación debe hacer sospechar de inmediato que se trata de una discusión sobre la idoneidad del control judicial de leyes penales -y, al final, efectivamente se trata en parte de eso-, sería apresurado empezar por analizar este mecanismo institucional, porque ello hace suponer que todo discurso que pretenda realizarse en control judicial tiene la misma identidad. Nuestro objeto de análisis no es, en se sentido, relativo (sólo) al mecanismo de control, sino antes a la pretensión misma de tender al control de la racionalidad de la identidad del sistema jurídico por medio del derecho 5 . Esto es: nos interesa preguntarnos por las posibilidades que tiene el derecho de controlar la racionalidad de su propia conformación.

La preocupación por el control jurídico de la racionalidad del derecho es especialmente intensa en el ámbito penal; justamente ello constituye al derecho penal en un objeto de interés en relación con preocupaciones de esta clase. Desde

\footnotetext{
5 Obsérvese que, por ahora, se trata sólo de la tendencia a la asunción de que es el derecho el que debe tender a controlar la racionalidad de su identidad pese a que ella sea provista desde afuera (por la política), y no en cambio de que tienda a establecer mecanismos que aseguren que la política se corrija a sí misma -algo que en el mundo anglosajón y, en particular, inglés tiende a ser enfatizado con el concepto de democracia que se corrige a sí misma (self-correcting democracy).
} 
su origen en la tradición del derecho natural racional, la ciencia del derecho penal ha encontrado una preocupación teórica marcada por la asunción del carácter problemático de la práctica que constituye su objeto de estudio ${ }^{6}$; esta asunción es, por cierto, el origen de la construcción de discursos críticos, pero también de la conformación de su identidad disciplinaria en base a preguntas de legitimidad.

Pragmáticamente considerada, la preocupación por la legitimidad del derecho penal puede ser descompuesta en al menos dos dimensiones: una pretensión de estructuración de discursos de explicación de legitimidad de la práctica de la punición estatal -esta pretensión pragmática encuentra su expresión en un discurso que, a grandes rasgos, se denomina "teoría de la pena"-, y una pretensión de estructuración de discursos de control en el mantenimiento de una identidad legítima de acuerdo a lo que el discurso de explicación legitimatoria determine - pese a que no hay usos generales de designación de esta pretensión teórica en sí, teorías tales como la teoría del bien jurídico o al principio del daño realizan una pretensión de esta clase ${ }^{7}$-. La primera pretensión derivada de la preocupación por la legitimidad del derecho penal puede ser así caracterizada como "reconstructiva" o "explicatoria", mientras que la segunda puede ser caracterizada como "crítica", "prescriptiva" o "de control".

En este artículo nos interesa hacernos cargo de la segunda pretensión en el ámbito del derecho penal, pero, para hacerlo, tenemos que contar con una comprensión más acabada de lo que caracteriza, para los efectos que nos interesan, a los discursos jurídicos con pretensiones críticas (o prescriptivas o de control). Como el concepto en cuestión se construye en oposición con una pretensión teórica paralela -la pretensión teórica de explicación de legitimidad-, podemos empezar por dar cuenta de la distinción.

En principio, una pretensión explicativa de una práctica puede distinguirse pragmáticamente de una pretensión crítica siguiendo la famosa conceptualización de Searle ${ }^{8}$ : un acto de habla descriptivo es verdadero si se ajusta $(f i t)$ a la realidad que pretende reconstruir, por lo que tiene una dirección de encaje (direction of fit) del enunciado hacia el mundo, esto es, pretende que el enunciado sea como

6 Expresivo de esta asunción es la imputación de un carácter "odioso" al castigo y a la coacción penal. Véase sólo KindHÄUSER (2009), p. 961; PAWLIK (2010), p. 59.

7 Sólo a modo de aclaración: me refiero aquí sólo a la así denominada "función crítica" (de control) del concepto de bien jurídico y no, en cambio, a la capacidad de contribuir a la sistematización racional de la Parte Especial por medio de la identificación de presupuestos comunes de punibilidad entre distintos tipos.

8 Searle (1979), pp. 3 y s. Véase ya antes Anscombe (1963), pp. 56 y ss. 
el mundo (aquí: la práctica) que intenta reconstruir; ese encaje determina la corrección del enunciado. Un enunciado prescriptivo no pretende, en cambio, ser verdadero en ese sentido, sino conseguir que el mundo se ajuste a aquello que el enunciado dispone, esto es, tiene una dirección de encaje inversa. Su propio éxito depende, por ello, de su capacidad de motivar a realizar el cambio del mundo que el enunciado pretende.

Por cierto, tratándose de prácticas sociales como el derecho y de teorías ligadas a esas prácticas, la aplicabilidad de la idea de dirección de encaje es más compleja que lo que la simple unidad del acto de habla sugiere. La idea de explicación de legitimidad o de reconstrucción, construida aquí en oposición a la pretensión crítica, que, en definitiva, nos interesa, pone de inmediato de relieve su pragmática más que descriptiva y los problemas asociados a la distinción entre explicación y crítica: el concepto mismo de "reconstrucción" supone ciertamente dar cuenta de un objeto con una identidad independiente de la teoría y en ese sentido tiene una dirección de encaje descriptiva, pero la teoría pretende a su vez alterar la identidad del objeto al tematizarla. Justamente por ello se trata de una práctica interpretativa ${ }^{9}$. La dirección de encaje parece ir, en este caso, hacia ambos lados -ella debe tener "equilibrio reflexivo" para ser una teoría convincente-, pero ello supone justamente capacidad de influencia en la comprensión de la práctica.

Esta doble dirección de encaje se ve posibilitada por el hecho de que su objeto de análisis no es un hecho bruto, sino una práctica social. En una práctica social, la pretensión misma de reconstruir la práctica participa de ésta -implica al menos una oferta de sentido respecto a lo que es la práctica puesta a disposición del resto de los actores que participan en ella- $y$, por ello, en algún sentido influye en su identidad de un modo mucho más intenso del que el uso del concepto de "zanahoria" incide en la identidad del objeto designado como zanahoria, pese a que suponga una comprensión común mínima que haga posible la existencia de la práctica ${ }^{10}$.

Las pretensiones pragmáticas de la teoría explicativa también parecen ser excesivamente complejas para poder ser explicadas a partir de la pura idea de dirección de encaje cuando uno se pregunta por el destinatario de la comunicación y la acción que se espera de él. Asumamos esta vez, para simplificar el punto, que la dogmática legal es la disciplina de reconstrucción teórica (caracterizable, por

9 La idea de prácticas interpretativas se encuentra originalmente en DwORKIN (1986), pp. 45 y ss.

10 MacCormick (1998), p. 308. 
ello, en relación con la pretensión de encaje de la teoría con el mundo), mientras que una teoría del bien jurídico o del principio del daño con pretensiones de ser aplicable en el control judicial de las leyes es el discurso crítico con pretensiones prescriptivas (o criticas). En principio, parece que la dirección de encaje inversa que caracteriza a la pretensión crítica o de control puede expresarse en el hecho de que el cumplimiento de las condiciones de verdad de un enunciado crítico implica el surgimiento de una obligación de realización de una acción institucional que cambia la práctica. Éste es el caso obvio del control judicial "fuerte"11, por medio del cual se declara inválida (o inaplicable) una regla hasta ahora considerada válida (o en principio aplicable) justamente cuando se cumplen las condiciones que permiten que el tribunal con competencia constitucional lo haga. Así, aquello que en una práctica institucional caracterizaría a un enunciado teórico con pretensiones críticas sería la generación de una obligación de cambio de la práctica por parte de un agente competente para ello, en caso de que se cumplan las condiciones de éxito del enunciado.

Sin embargo, si uno mira más de cerca sus pretensiones, la cuestión parece no ser realmente distinta en el caso de la dogmática (legal): un enunciado dogmático exitoso también puede tener la pretensión pragmática de obligar al funcionario competente a la realización de acciones institucionales que modifican la práctica. Esa obligación sólo la puede constituir en caso de que reconstruya correctamente el derecho y verifique que la práctica judicial no sigue aquello que el derecho dispone. Pero, si tiene éxito, el resultado de su éxito es la obligación de cambio de la práctica: la teoría parece así tener la doble dirección de encaje teoría-mundo ${ }^{12}$ (porque ese ajuste es condición de éxito) y mundo-teoría (porque ése es el resultado de su éxito).

Lo anterior tiene una explicación ciertamente sencilla: la dogmática plantea, por su naturaleza misma, enunciados prescriptivos, ya que ella reconstruye las normas que conforman a una práctica de prescripción como el derecho. Así, al reconstruir el contenido de un sistema de normas jurídicas determinado, la dogmática señala que ciertas normas existen y, por ese mismo hecho, tiene pretensiones pragmáticas prescriptivas ${ }^{13}$. Tratándose además de una práctica institucional en que se identifican actores con competencias especiales en la realización de

11 Véase a este respecto sólo Tushnet (2003), pp. 361 y ss.

12 "Mundo" aquí no significa más que objeto de análisis independiente de la teoría.

13 Véase a este respecto Christensen (1989), pp. 277 y ss. 
acciones al interior de la práctica ${ }^{14}$, es siempre posible decir que un enunciado dogmático puede tener por pretensión identificar normas no evidentes y, con ello, posibilidades de aplicación no conocidas, estableciendo con ello normas (si se da el caso X, el juez debe aplicar la consecuencia Y); y, de este modo, obligaciones de acción que cambian institucionalmente la práctica.

No es, de este modo, sólo el hecho de que el derecho sea una práctica social -cuya artificialidad implica que se encuentra abierta al cambio por medio de la participación en la práctica-, sino también que se trata de una práctica institucional con atribuciones de competencias en la realización de acciones que implican cambiar la práctica lo que parece hacer colapsar la distinción entre explicación y prescripción. También el discurso de explicación de legitimidad tendría pretensiones de hacer cambiar la práctica (para adaptarla a aquello que se define como legítimo) y ello además tendría un destinatario especial en sujetos con competencias para la realización de acciones que en sí cambian la práctica. Con ello, ninguna de las posibilidades que hemos explorado para distinguir pragmáticamente entre teorías explicativas y teorías críticas parece tener perspectivas de éxito.

Por cierto: nada de lo anterior impide trazar distinciones que no son pragmáticas, sino cognitivas. El enunciado reconstructivo (“dogmático”) exitoso tiene así ciertamente condiciones de éxito distintas al enunciado crítico exitoso; a grandes rasgos: uno tiene que ajustarse al derecho vigente en general, mientras que el otro tiene que ajustarse a las condiciones jurídicas de constitución de derecho válido. Lo que nos interesa verificar aquí es que el éxito de uno u otro implica algo similar: obligación de ajuste de la práctica al enunciado fundado en la teoría respectiva.

Pese a estas dificultades, existen elementos propios del derecho moderno que permiten dar cuenta de la relevancia de la distinción en una dimensión pragmático-institucional. Esto puede apreciarse de inmediato si uno considera la función de la teoría frente a la práctica en distintos momentos histórico-institucionales. Asumáse que el derecho premoderno puede ser caracterizado frente al derecho moderno bajo la distinción entre veritas non auctoritas facit legem (la validez del derecho proviene de su corrección, no de la autoridad que lo dicta) y auctoritas non veritas facit legem (la validez del derecho depende de sus condiciones autoritativas de producción). Pese a que la cuestión es seguramente mucho más compleja en los dos momentos, la simplificación de la distinción nos sirve para ilustrar las particularidades del problema en cada uno de estos momentos.

${ }^{14}$ La caracterización de práctica institucional a partir de la concesión de poderes de segundo orden de control sobre las reglas también se encuentra en MACCormicK (1998), pp. 324 y ss. 
Bajo el derecho premoderno, pretensión crítica y pretensión reconstructiva no pueden ser distinguidas al interior de la práctica de constitución del derecho por razones internas a la práctica ${ }^{15}$ : participar en la práctica de reconstruir el derecho es participar en la práctica de contribuir a que tenga una identidad debida. Eso no quiere decir que no puedan realizarse enunciados teóricos con pretensiones pragmáticas descriptivas: basta que en ese caso se asuma posición de observador. Pero la asunción de la posición de observador implica por sí misma no participar en la práctica. Ella se define de este modo a sí misma a partir del colapso, interno a la práctica, entre lo que ella es y lo que ella debe ser.

Éste no es, en cambio, el caso del derecho moderno, y esto es sumamente sencillo de observar si nos desentendemos por ahora de la dimensión institucional ligada a la posición de los jueces. El derecho moderno opera estableciendo la distinción interior a la práctica entre validez y legitimidad, con lo que es perfectamente posible orientarse a entregar la mejor explicación posible sobre las ideas de legitimidad que inspiran a instituciones positivas (válidas) y sostener, al mismo tiempo, que ellas debieran ser distintas. Aquello que hace posible distinguir pretensiones críticas y pretensiones reconstructivas, es, por ello, la distinción cognitiva, entre derecho que es y derecho que debe ser, que caracteriza al derecho moderno. Esa distinción se ve asegurada por el reconocimiento de ajenidad en la conformación de los rasgos esenciales de la práctica por parte del participe reconstructivo (el dogmático): este ciertamente incide sobre la práctica y altera (o pretende alterar) su identidad al hacerlo, pero sus rasgos esenciales no son disponibles por él por medio de investigaciones cognitivas, sino que son el resultado de un acto de voluntad ajeno.

Como la validez de las reglas que informan la práctica no depende del reconocimiento de su condición de realización de un ideal de justicia, sino del cumplimiento de condiciones procedimentales, es ciertamente posible entender en qué consiste la práctica (y, con ello, contar con una reconstrucción de la práctica) y, al mismo tiempo, asumir que ella debiera ser algo distinto a lo que es. Ejemplo: un penalista puede asumir que el sistema penal es en general legítimo porque es necesario para la protección de ciertos bienes, o para mantener un orden determinado o porque los delincuentes merecen ser castigados o cualquier idea de esta clase. El mismo autor puede perfectamente decir, sin embargo, que algunas

15 Por supuesto: un partícipe puede cuestionar la idea de que el derecho deba ser el derecho justo, en cuyo caso su teoría no cumple los requisitos de validez para ser considerada participación en la práctica, con lo que tendría una pretensión crítica pura. 
normas que informan la práctica -y que, por ello, son parte de la práctica, porque ella se estructura sobre una idea de validez- no debieran ser o debieran ser de otro modo, ya que así se ajustarían mejor al ideal que las informa o debiera informarlas. Uno puede intentar explicar teóricamente de distintas formas este fenómeno: ello puede ser visto como parte de la práctica o como actividades ajenas, periféricas a la práctica, con lo que el partícipe de nuestro ejemplo llevaría a cabo una especie de desdoblamiento pragmático al asumir posición de observador. Hasta aquí sólo nos interesa dar cuenta de las razones estructurales que hacen posible que el partícipe en la práctica reconstructiva pueda, al mismo tiempo, asumir una actitud crítica: la internalización de la distinción entre validez y legitimidad en la observación del derecho moderno es aquello que permite trazar la distinción.

Volvamos ahora al problema de pragmática institucional que nos ocupa. El tipo de discursos que nos interesa revisar tiene particularidades que exceden los rasgos peculiares de un discurso crítico en relación al derecho moderno y que pretenden ser expresadas aquí con la idea de que se trata de discursos teórico-jurídicos con una orientación crítica. Es decir: los discursos que nos interesan se caracterizan no sólo por asumir que existe una práctica con una constitución distinta a la debida, sino también por pretender influir directamente en la conformación de la práctica como ella debiera ser. Para explicar esto, podemos empezar por dar cuenta del hecho de que no es una peculiaridad de las disciplinas jurídicas el poder realizar discursos críticos del derecho vigente. Realizar discursos respecto a la identidad que debieran tener nuestras normas o instituciones puede también ser realizado por medio de discursos que seguramente calificaríamos como "ajenos" o "no jurídicos" y, con ello, los situaríamos en tradiciones teóricas no jurídicas como la filosofía política, la teoría política o la sociología crítica. Todos estos discursos pueden asumir la distinción entre legitimidad y validez (con lo que asumen la identidad central al derecho moderno) y criticar las instituciones vigentes, señalando que son (o, mejor, que el mundo institucional es) algo que no debe(n) ser. Si se asume, sin embargo, la distinción entre validez y legitimidad, ninguno de esos discursos tiene potencial para influir directamente en la identidad de la práctica; la crítica presupone que ella no afecta la validez.

Ejemplo: el filósofo abolicionista que afirma que el derecho penal no merece reconocimiento está, en ese mismo acto, prestándole reconocimiento como una institución que existe. Se trata, por ello, de un discurso crítico conformado bajo las distinciones internas al derecho moderno entre validez y legitimidad. Su "no debe ser" sólo puede ser entendido, desde el punto de vista del derecho, como un llamado al cambio de nuestras prácticas institucionales respecto a quien tiene 
competencia o poder para alterar la identidad de la práctica -sea el legislador formal o el pueblo como soberano de la nación o alguien más-. Pero su carácter no jurídico se expresa en el hecho de que, desde el punto de vista del derecho, el interlocutor apelado no tiene obligaciones exigibles de realizar ese cambio: eso es política moderna.

Un discurso crítico-jurídico tiene, en cambio, pretensiones de influir directamente en la conformación de la identidad de la práctica pese a que reconozca la validez de la institución a la cual se le atribuye una identidad que no debe ser. La clave se encuentra, por lo tanto, en la idea de "pretensión de influencia directa": ella está presente en lo que hemos denominado "discurso jurídico crítico del derecho" y se encuentra ausente, en cambio, en el discurso no jurídico crítico del derecho. Mientras que, desde el punto de vista de la práctica, el discurso crítico no jurídico no pretende más que influir del mismo modo en que todo ciudadano teóricamente podría hacerlo -como apelación a la política, a cuyo respecto la razón no vincula-, el discurso jurídico-crítico apela a actores con competencia en la determinación vinculante de la identidad de la práctica y que además se encuentran vinculados por un discurso crítico verdadero: si las condiciones de verdad del discurso se cumplen, el actor se encuentra al menos teóricamente obligado a influir en la práctica del modo en que el discurso lo dice.

La existencia de discursos crítico-jurídicos parece de este modo acercar al derecho moderno al derecho premoderno. Ambos se distinguen, sin embargo, no sólo en las condiciones de éxito de un enunciado crítico (a grandes rasgos: en el derecho premoderno bastaría con que demostrara qué reglas generalmente reconocidas no son plenamente racionales, sino que podrían tener una mejor forma, mientras que en el derecho moderno deben cumplirse condiciones especiales de control que son más estrictas que la simple existencia de mejores alternativas), sino ante todo en que el éxito del enunciado crítico premoderno es una reconstrucción de la práctica y, con ello, la cambia en el mismo acto, mientras que en el derecho moderno sólo constituye una obligación condicional de modificación autoritativa de la práctica respecto de reglas a las que se les reconoce (hasta ese acto) validez. El discurso reconstructivo sólo puede cambiar la práctica como parte de una interpretación, sin suponer por ello un verdadero cambio en su identidad; el discurso crítico cambia la práctica, en cambio, por medio de actos que suponen variación de identidad porque se reconoce una competencia para ello.

Estas distinciones tienen tres rendimientos relevantes para el análisis que queremos llevar a cabo. En primer lugar, ellas nos permiten especificar el objeto de análisis del artículo: nos interesa hacernos cargo de discursos que pretenden 
obligar a la realización de acciones autoritativas en las que se asume que sólo ellas cambian la práctica. Éste no parece ser el caso de los discursos reconstructivos: como el discurso reconstructivo pretende dar cuenta de la identidad de la práctica, no sólo se asume que su éxito no implica disposición de algo que se había reconocido, sino que el éxito (ilocucionario) no depende de su aceptación por el funcionario con competencia para cambiar la práctica. Si la teoría es exitosa, entonces ella dio cuenta de la verdadera identidad del derecho y, pese a que ello no tenga efectos hasta ser aplicado como debiera serlo, no es el acto autoritativo del juez el que cambia la identidad del derecho. En cambio, el tipo de discursos que nos interesa revisar supone que su éxito implica el establecimiento de obligaciones de modificación de la identidad del derecho vigente ${ }^{16}$, asumiendo que la identidad del derecho vigente es la misma mientras no se realiza la acción institucional a la que se está obligado.

Pese a lo anterior, existe una disciplina que hace colapsar la distinción entre discurso reconstructivo y discurso crítico: la dogmática constitucional (de las acciones constitucionales). El segundo rendimiento de las distinciones trazadas en este apartado es precisamente permitir dar cuenta de esta peculiaridad de la dogmática constitucional. La razón de este colapso es sumamente sencilla de explicar: como, a diferencia de las otras ramas del derecho, la dogmática constitucional (de la revisión judicial) tiene por objeto reconstruir normas que obligan o al menos habilitan a la ejecución de acciones cuyo objeto es precisamente privar de validez a normas vigentes, sus discursos reconstructivos (del derecho constitucional) son al mismo tiempo discursos críticos del derecho legal; el objeto mismo de su análisis tiene esa doble dirección. Sobre esta peculiaridad volveremos más adelante, ya que ella le permite al derecho constitucional eludir parte de las dificultades que afectan a los discursos críticos elaborados bajo la dualidad discurso explicativo/ discurso crítico asumida por la dogmática penal.

Por último, las distinciones trazadas nos permiten especificar el contenido necesario a todo discurso crítico jurídico. Dada su orientación a la alteración del derecho vigente por sujetos competentes para ello, el discurso debiera especificar al menos tres elementos: quién es su interlocutor $-\mathrm{o}$, lo que es lo mismo, qué autoridad (o sujeto: puede ser la comunidad científica misma) tiene competencia para alterar el derecho vigente-; qué condiciones deben cumplirse para que

\footnotetext{
16 Aquí hago uso del concepto de "derecho vigente", y no de "práctica del derecho", para mostrar el modo en que los discursos críticos influyen sobre el derecho reconocible por criterios formales y no, en cambio, en el tipo de aplicaciones que son reconocidas.
} 
el interlocutor se encuentre obligado a modificar el derecho vigente, y el modo en que se constituye formalmente la obligación de cambiar el derecho vigente -a grandes rasgos: qué acción, procedimiento jurídico o, en general, proceso identificable gatilla la competencia en cuestión-. No todos los discursos que se definen a sí mismos como "crítico-jurídicos" cumplen con estas condiciones. De un modo evidente, sí lo hacen los discursos de control constitucional elaborados por la dogmática constitucional: ellos hacen referencia a acciones especialmente regladas por los sistemas jurídicos ${ }^{17}$ (acciones de inaplicabilidad, control preventivo o represivo de constitucionalidad) para vincular sus propias teorías sobre las condiciones de realización de ese control, como reconstrucciones de las condiciones de éxito de esas acciones. En cambio, en el caso de discursos elaborados por la dogmática penal, prácticamente nunca se especifica el destinatario de la obligación de control ni las condiciones de ejercicio de esa competencia -de hecho, no tiende ni siquiera a afirmarse de modo enérgico si alguien tiene o no competencia para cambiar la práctica aplicando la teoría en cuestión ${ }^{18}-y$, con ello, sólo se especifican de un modo muy general las condiciones de éxito de un control que no se encuentra antes definido.

Por supuesto, bajo esta especificación del objeto de análisis uno podría de inmediato imputarle a las teorías críticas elaboradas por las ciencias penales ${ }^{19}$ un grado tal de indiferenciación que las haría desde un inicio inidóneas para cumplir un rol crítico-institucional. Pero esto sería demasiado apresurado por dos razones. En primer lugar, con independencia de lo que asuman sus representantes, las teorías en cuestión podrían perfectamente tener rendimiento institucional como condiciones de éxito de controles judiciales. Su falta de especificación procedimental no implica que sean incompatibles con los mecanismos que conocemos que

\footnotetext{
17 Ejemplo de regulaciones sobre acciones constitucionales: artículo 25 C números 1, 6 y 8 de la Ley Orgánica Constitucional del Tribunal Constitucional chileno en relación con el artículo 93 números 1, 6 y 7 de la Constitución Política; art. 93 inciso segundo número 2 en relación con el $\$ 13$ número 6 y $\$ \$ 76$ y ss. de la BVerfGG (Ley del Tribunal Constitucional Federal alemán).

18 Ilustrativo respecto a esta ambigüedad, Roxin (2006), $\$ 2$ No 92 y ss. Enérgicos, en cambio, respecto a la aplicabilidad por parte del BVerfG del control de legitimidad del derecho penal, GRECO (2008), pp. 235 y ss.; SCHÜnemann (2003), pp. 141 y ss. Más allá de la afirmación, no hay mayor tratamiento diferenciado de las condiciones de producción del control en cuestión.

19 En esta categoría incluyo a la literatura en lengua inglesa sobre el derecho penal, pese a que la diferenciación disciplinaria continental no tenga lugar con la misma intensidad en ese contexto. Así, mientras la teoría del bien jurídico puede considerarse un discurso directamente elaborado por la dogmática penal alemana, el principio del daño tiene su origen en la literatura filosófico-política. Pese a ello, por razones que veremos más adelante, ambos serán expuestos en conjunto.
} 
tienen pretensiones de control del output de la legislación. Además, en segundo lugar, las teorías elaboradas por la dogmática jurídico-penal son el paroxismo de un modo de aproximación sustantivo a la racionalización de la legislación que es, en sí, problemático, pero que tiende a vincularse al control judicial. Si bien las definiciones más precisas de la dogmática constitucional hacen que parte de las críticas que pueden realizarse a esta clase de teorías (en general: ceguera frente a lo delicada que resulta la adjudicación de poder político que supone) se vean mitigadas, parte de las razones que explican la falta de rendimiento de controles sustantivos pueden verse de mejor forma cuando se lo analiza en el caso exagerado en que ello tiene lugar. Ésta es la segunda razón del interés de las teorías penales: ellas exageran el punto respecto a que los productos políticos deben ser controlados en su mérito y, con ello, demuestran de un modo tal vez ingenuo las deficiencias de este modo de aproximación que son, en cambio, escondidas por la (mucho más consciente de las dimensiones institucionales de estos problemas) dogmática constitucional.

\section{Los discursos de control}

En este apartado nos interesa reconstruir y criticar directamente a las dos clases de discursos jurídico-críticos que hemos identificado a partir de las distinciones trazadas en la sección anterior: la primera clase opera sobre la distinción entre discurso explicativo y discurso crítico, mientras que la segunda hace colapsar la distinción por trabajar sobre el derecho constitucional. La crítica se centra, por cierto, en la capacidad de rendimiento institucional del control judicial sustantivo. Pero las razones de esta incapacidad no son exactamente las mismas en los dos casos. Por ello empezaremos reconstruyendo el acercamiento penal y criticando aquellos aspectos específicos que pueden serle criticados. A continuación expondremos a grandes rasgos la identidad de los discursos de control elaborados por la dogmática constitucional. Finalmente criticaremos la falta de eficacia de este acercamiento en el ámbito penal -no centrándonos por ello en los conocidos problemas de legitimidad política del control judicial-, lo que es por cierto también extensible al acercamiento penal.

\section{II.1. El acercamiento penal: la tesis de la continuidad}

Como hemos visto, la constante preocupación de las ciencias jurídico-penales por la legitimidad de su objeto de análisis tiende a expresarse en las dos dimen- 
siones pragmático-institucionales que hemos analizado: construyendo discursos explicativos de legitimidad con pretensiones de influencia discreta sobre la práctica del derecho penal -la teoría de la pena-, y construyendo discursos críticos en el sentido analizado en el apartado anterior respecto a las normas del derecho penal-teoría del bien jurídico, adopción del principio del daño, etc.

Crucial en el análisis del modo en que procede la academia penal al construir sus discursos críticos es advertir que, en general, no se trata más que de adaptaciones pragmáticas (en el sentido identificado en la primera sección) de sus tesis desarrolladas como discurso explicativo. Esto es lo que denominaremos la tesis de la continuidad: las ciencias penales asumen que sus discursos críticos deben construirse sobre la explicación de legitimidad que obtengan de su discurso teórico-explicativo (la teoría de la pena). Ello implica la atribución de primacía estructural a la teoría de la pena. Como en su propia identidad disciplinaria, la teoría de la pena es vista como determinante, la tesis de la continuidad implica, en los hechos, que los discursos críticos se construyan asumiendo decisiones metodológicas que provienen de la teoría de la pena.

El discurso de la teoría de la pena asume, sin embargo, que debe entregar una explicación sustantiva a la legitimidad de la práctica que analiza. Ésta es una característica determinante de la identidad disciplinaria del estudio del derecho penal tanto en la tradición continental como en la tradición del common law. La teoría de la pena es un discurso legitimatorio sustantivo ${ }^{20}$ : ella no pretende explicar la legitimidad de la práctica punitiva a partir de derivaciones formales de legitimidad por reconducción a un actor o a procedimientos determinados, sino porque el contenido del derecho penal merece (o no) reconocimiento en sí. Ello tiende a ser explicado de distintos modos: por medio de argumentos morales consecuencialistas (se trata de medios necesarios al cumplimiento de un fin que es visto, por sus consecuencias, como valioso), por medio de argumentos morales deontológicos (y su expresión en una teoría del merecimiento) o, en su mejor versión, por medio de argumentos de filosofía del Estado. El aspecto central que es traspasado de este modo a los discursos críticos es el carácter sustantivo que asume-como cuestión de hecho- la teoría de la pena.

Nos interesa, en ese sentido, criticar el potencial de rendimiento de discursos críticos construidos bajo la tesis de la continuidad asumiendo un punto de

20 Desde las otras disciplinas del derecho público -cuyas explicaciones de legitimidad asumen, con mayor o menor éxito, el aspecto dinámico de la cuestión-, tiende a partir de este rasgo a decirse que el derecho penal ha permanecido siendo una anomalía (un Fremdkörper) a causa de su orientación propia del derecho natural racional a la reconstrucción sustantiva. Véase sólo GärdITZ (2010), pp. 332 y ss.; el mismo (2015), pp. 39 y ss. 
partida sustantivo. Asumamos, además, que el punto de partida sustantivo es al menos mínimamente convincente, esto es, que pretende entregar una explicación (sustantiva) a la legitimidad de una práctica considerando todos sus aspectos esenciales. Esto no sucede, por ejemplo, cuando se trata de un acercamiento puramente moral: se explica por qué el castigo, como acción discreta, puede tener valor moral, como si ello sirviera del todo a legitimar una práctica de dominación política tan específica como el derecho penal ${ }^{21}$. Esta clase de teorías no nos interesa. Nos interesa más bien reflexionar sobre la influencia de la teoría de la pena en discursos críticos cuando cumpla dos condiciones mínimas: (i) ella debe asumir un punto de vista institucional, en el sentido de tener conciencia de que las discusiones sobre conceptos como la pena no son morales desnudas, sino que relativas a configuraciones jurídicas determinadas y, en particular, al Estado como unidad de dominación territorial monopólica de la violencia retributiva; pero (ii) ella debe entender que el modo de responder la pregunta por las razones por las que reconocemos legitimidad a estas instituciones es preguntándose directamente por las condiciones sustantivas de legitimidad de éstas ${ }^{22}$. Ésta es la forma en que uno puede entender afirmaciones tales como que la pena "sólo puede ser legítima si se orienta exclusivamente a la prevención" y cuestiones similares que caracterizan a la teoría de la pena, pese a ser planteadas en literatura que no es política, sino (al menos en apariencia) jurídica ${ }^{23}$.

21 Crítico respecto de esta clase de acercamientos (hoy en día dominantes) en el mundo anglosajón, MuRPHY (1987), pp. 510 y s.; Binder (2002), pp. 321 y ss.; RAMSAY (2006), pp. 29 y ss.

22 Ilustrativo, Ramsay (2014), p. 62. Al respecto, con mayor detalle, véase mi artículo "Sobre el discurso de legitimación política de la pena estatal" a ser publicado en la Revista de Derecho de la Universidad Austral.

23 Por ello, tampoco nos interesa aquello que podría llamarse una teoría de la pena vacía, esto es, una teoría que reenvíe a definiciones de fines o razones legitimatorias que son ajenas a ella. Éste es un modo de proceder especialmente popular (y, en principio, institucionalmente correcto) de la literatura de la denominada escuela clásica (y corrientes afines) durante el Imperio Alemán. Así, por ejemplo, Beling (1978), pp. 36 y s.; JelLineK (1908), pp. 60 y ss., 114 y ss.; Merkel (1892), pp. 15 y s.; SCHMidt (1895), pp. 56 y ss.; el mismo (1923), p. 411. Completamente explícito, MARX (1972), pp. 507 y s. Entre nosotros similar, por referencia a Beling, MaŃALICH (2015), pp. 19 y ss. En la discusión contemporánea, este (correcto) vacío de contenido es asumido tanto por las distintas variantes de la teoría de la prevención general positiva (especialmente claro en ApPeL (1996), pp. 19, 428 y ss.; Gärditz (2010), pp. 357 y s., como por la fórmula generalmente utilizada por el BVerfG para describir el sentido de la pena -véase BVerfGE 27, 18 (29) (derecho administrativo sancionatorio); 39, 1 (46) (aborto 1); 45, 187 (asesinato y presidio perpetuo); 88, 1 (257) (aborto 2); 120, 224 (241f.) (incesto) - o en su construcción sociologizante en JAKOBS (1991), 1/20. En todos estos casos, la teoría no asume mayores definiciones político-filosóficas sustantivas, con lo que la tesis de la continuidad no puede operar. 
Asumida que sea esa identidad -lo que no implica declarar que todo discurso que se presente a sí mismo como "teoría de la pena" comparta esa identidad, aunque en general lo haga-, sería posible tomar un camino fácil y declarar un acercamiento de esta clase como inadecuado en sí al estudio de la legitimidad del derecho: una definición sustancial de las condiciones de validez de reglas formadas en una práctica de creación de normas en base a forma no podría ser adecuada sino como discurso político, es decir, precisamente como parte de lo no jurídico. Ese diagnóstico tiene, por cierto, mucho a su favor, pero se desentiende del hecho de que la práctica producida por decisiones políticas que pueden ser consideradas externas a ésta -la capacidad de disposición al menos teórica de la práctica que tiene la legislación hace que sea en algún sentido externa a ésta- se encuentra sujeta a cambios que pueden ser producidos por dentro desde el momento mismo en que ponemos interpretaciones a disposición de los otros partícipes -la objeción dworkiniana-. Nosotros no necesitamos en este contexto, sin embargo, valorar a la teoría de la pena en sí, sino sólo la capacidad de que discursos que asuman sus compromisos metodológicos puedan ser fundamentados y puedan tener éxito como discursos de control institucional. En lo que sigue, se trata así de demostrar la inadecuación del paso de un discurso reconstructivo sustantivo -cuyo potencial teórico en ese ámbito me parece limitado, pero ello no puede ser demostrado aquí- a un discurso de control institucional.

\section{II.2. Critica a los discursos criticos construidos sobre la tesis de la continuidad}

El problema central de los discursos críticos construidos en continuidad con la teoría de la pena es que necesitan de definiciones previas que no pueden fundamentar. Esto es algo que, como veremos, es traspasado por la teoría de la pena a sus brazos de combate institucional (teoría del bien jurídico, harm principle).

Comencemos revisando el problema en su origen, esto es, al interior de la teoría de la pena ${ }^{24}$. En tanto discurso sustantivo de explicación de legitimidad, la teoría de la pena necesita asumir que la institución que ella tematiza es legítima por razones de justicia. En general, ello conduce a la asunción de una comprensión estática no sólo de la institución específica pena, sino también del modo global

24 Véase, a este respecto, el artículo "Sobre la legitimidad política de la pena estatal" a ser publicado en la Revista de Derecho de la Universidad Austral. Los pasajes que siguen presentan una versión resumida de los hallazgos desarrollados extensamente en ese artículo. 
de organización institucional general del que participa, a saber, del Estado. El Estado es así visto como una entidad cuya justificación es fija porque su identidad es, en sus aspectos esenciales, fija: el Estado se justificaría porque tiende al otorgamiento de bienes preestatales tales como seguridad, bienestar o libertad a sus ciudadanos. Una fundamentación de esta clase tiende a ser hecha extensible a las instituciones que constituyen parte de la identidad de esta comprensión del Estado, como la pena. Como el discurso de justificación general del Estado es, sin embargo, demasiado abstracto para explicar de inmediato la configuración de una institución específica, la filosofía del Estado tendía a precisar las conclusiones por medio de su concreción en definiciones de objetivos estatales ("teoría de los fines del Estado") y en el vínculo de sus instituciones con el cumplimiento de estos fines ("teoría de los fines de la pena"). La producción de una explicación de la legitimidad de una institución depende así de la demostración de su carácter necesario al cumplimiento de uno de esos fines esenciales (la seguridad) al Estado; la toma de medidas que exceden o que no tengan vinculación con lo necesario sólo puede asumir una explicación por poder, pero no debiera ser merecedora de reconocimiento 25 .

Aunque es probable que por razones ideológicas no siempre se esté dispuesto a reconocer los méritos de este modo de razonamiento, su poder de convicción es indudable y, como reconstrucción general de la fundamentación sustantiva del poder represivo estatal, sigue siendo un modo de pensamiento al menos estructuralmente hegemónico ${ }^{26}$ : no sólo la teoría de la pena, sino también la cultura en general, asocia el derecho penal al otorgamiento de seguridad.

Pese a lo anterior, los problemas en la fundamentación de las instituciones a partir de esta reconstrucción de filosofía del Estado se observan cuando uno se

\footnotetext{
25 En la literatura del siglo XIX, especialmente nítidos en la adopción de una estructura de argumentación de esta clase, Bauer (1996a), pp. 1 y ss.; el mismo (1996b), pp. 25 y ss.; Feuerbach (1966), pp. 38 y ss.; el mismo (1986), pp. 36 y ss.; Von Grolman (1996), pp. 4 y ss.; Von Mohl (1866), pp. 9 y ss. Pese a la equivalencia estructural, prácticamente todos estos acercamientos asumen una definición del estado de cosas cuya protección es necesaria - el estado civil o de derecho- que tiene un contenido sustantivo mucho más denso que en el caso de Hobbes. Eso no le quita su equivalencia estructural: se sigue tratando de la entrega de una definición estática del Estado y de una construcción de una relación de necesidad con la pena para su mantenimiento.

26 Este carácter hegemónico en lo relativo a las teorías de la pena es también constatado por GRECO (2009), pp. 17 y ss.
} 
acerca a sus conceptos centrales ${ }^{27}$ : seguridad, necesidad son conceptos que son presentados como un contenido propio, anterior a la configuración del poder del Estado. En su origen, en la tradición del derecho natural racional, asunciones de esta clase eran definitorias del acercamiento mismo que se adoptaba respecto al derecho: la distinción entre lo prepolítico, a cuyo respecto los arreglos políticos y el derecho debieran realizarse, y los arreglos políticos (incluyendo el derecho), cuyo objeto es precisamente permitir el aseguramiento de objetivos prepolíticos, era parte esencial del discurso ${ }^{28}$. Pero, por supuesto, no puede decirse que el Estado que conocemos nosotros y el orden provisto por éste tenga una identidad estática ${ }^{29}$. Ello se explica no sólo por la complejidad que la organización institucional ha adquirido y que impide realizar juicios bajo la forma sencilla de la racionalidad instrumental medio-fin ${ }^{30}$, sino también porque el Estado moderno no se define sólo por su condición de unidad territorial de dominación monopólica, sino por unir esa dimensión de poder a prácticas políticas centralizadas ${ }^{31}$. Ello hace que los conceptos centrales de seguridad y de necesidad que sustentan la argumen-

27 Expresado como crítica general a la teoría de los fines del Estado, decisivamente convincente ya JelLiNEK (1960), pp. 227 y ss., pp. 236 y ss.; MeYER y ANSCHÜtz (2005), p. 55. En la literatura actual véase sólo la reciente monografía de WISCHMEYER (2015), pp. 184 y ss., con numerosas referencias.

28 Convincente a este respecto, Menke (2015), pp. 56 y ss.

29 Ésta es justamente la razón por la que su definición tiende a ser complementada con su carácter "democrático y social" o fórmulas de esa clase, las que son utilizadas para especificar los fines que el Estado debiera cumplir y que podrían ser determinados por simple reflexión sustantiva.

30 Fundamental en la demostración de la incapacidad del modelo de la racionalidad instrumental bajo reconstrucciones de fines y medios para juzgar adecuadamente organizaciones complejas, LUHMANN (1991), pp. 156 y ss. En la dogmática penal alemana (y por derivación: hispanohablante) es usual encontrar reacciones frente a esta crítica -encarnada en la obra de GÜNTHER JAKOBS- que implican la afirmación de que ella sería "reaccionaria" cuando no "totalitaria". Al respecto véase sólo Silva SáncheZ (2006), pp. 121 y ss., con ulteriores referencias. Ello se vincula, por cierto, a disputas académicas de escuelas y, por ello, no es siempre racional. Pero es difícil advertir desde un inicio qué puede tener de reaccionario el simple hecho de mostrar que un esquema de control de legitimidad política es estructuralmente insuficiente. Por supuesto: ese esquema tiende a unirse a una cierta orientación liberal y, por ello, sus partidarios sienten que la crítica es una crítica a la ideología liberal, utilizando así la designación retórica de lo que siente como su negación para reaccionar: el totalitarismo. Ello demuestra que aquí no hay más que pura retórica política. Y lo que es peor: esa retórica política esconde el hecho de que el esquema excesivamente simple utilizado para controlar las decisiones políticas hace invisible los problemas de legitimidad sistémicos que afectan al derecho penal en sociedades desiguales.

31 En este sentido ya Heller (1971), pp. 248 y ss., 433 y ss. El reconocimiento del Estado como forma más desarrollada de la eticidad -a su vez el último estadio en el desarrollo del espíritu objetivo- y, en ese sentido, la concesión de una posición sistemáticamente subordinada a éste a la sociedad civil, en los $\$ \$ 268$ y s. de HeGEL (1986), expresa precisamente esta característica. 
tación en base a esta estructura no puedan asumir contenido fijo: qué es aquello que requiere de seguridad en el Estado necesita de una definición previa, a cuyo respecto el postulado de existencia natural es abiertamente inverosímili2.

Estas asunciones se reproducen en discursos de control que se construyan sobre continuidad con la teoría de la pena. La continuidad puede ser de inmediato verificada cuando se revisa el mantenimiento de las mismas asunciones de filosofía del Estado en su brazo combativo. Así, si una teoría de la pena prevencionista funciona sobre la base de la definición de fines inherentes al Estado -la pena es legítima en la medida en que contribuya a la prevención de delitos, ya que ello permitiría proteger bienes relevantes o aumentar el placer global o realizar la idea de justicia o lo que sea-, la teoría de control construida en continuidad con esta tiende a simplemente expresar esos hallazgos, declarando ilegítimas configuraciones que adviertan como no orientadas a esos fines - pudiendo, por cierto, agregar condiciones de control tales como que "evidentemente" no se orienten a ello-.

El problema debiera ser de inmediato visible: la teoría necesita aquí de definiciones previas a la constitución del orden estatal sobre lo que es seguridad digna de protección para funcionar, pero en un Estado moderno esa definición se encuentra entregada a la política. Existen aspectos que evidentemente se enmarcan dentro de cualquier definición de seguridad bajo nuestras condiciones culturales: no es controversial, por ejemplo, que evitar que los ciudadanos sean intencionalmente asesinados es un objetivo legítimo, del mismo modo en que no es controversial que la orientación del Estado a asesinar a sus ciudadanos (al menos sin vínculo con la realización de delitos graves) es inadmisible. Pero no es esta clase de decisiones lo que debe controlar un discurso crítico, sino cuestiones controversiales: ¿qué expectativas se protegen en el mercado?, ¿qué comportamientos sexuales agresivos (y con quién) se encuentran prohibidos y pueden ser castigados con pena? Como discurso crítico, los brazos combativos de la teoría de la pena parecen así manifestarse como inherentemente políticos y, con ello, como discursos que no pueden ser jurídicos de control.

Esto debiera ser en principio suficiente para descartar la capacidad de rendimiento de las teorías en cuestión: ellas necesitan de definiciones políticas de lo que es digno de protección y necesitan por ello atribuirse competencia sobre esas definiciones. El representante de la teoría del bien jurídico puede así afirmar que sólo ciertos fines pueden ser perseguidos por el Estado, pero ello requiere la

32 Entre nosotros, también crítico respecto del desentendimiento de la dependencia política del derecho penal, Mir PUig (2006), pp. 95 y ss. 
definición previa de fines legítimos e ilegítimos del Estado, sin que tenga nada más que esa opinión política en su apoyo ${ }^{33}$. Como veremos más adelante, el desconocimiento de competencia al legislador que ello implica augura que no tenga éxito institucional, precisamente por asumir una posición política conflictiva. Pero por ahora no necesitamos revisar todavía eso, sino el mero hecho de que la teoría no tiene base en la fundamentación de las premisas que la soportan. Un control teórico institucional construido así con continuidad con explicaciones de legitimidad sustantiva no parece poder fundamentarse.

\section{II.3. La tentación constitucional y el problema de la fundamentación}

Pero tal vez esa conclusión sea demasiado apresurada. El derecho contemporáneo pone a disposición de los partícipes de las prácticas jurídicas argumentos ulteriores que pueden presentarse como no políticos, a saber, las definiciones del derecho constitucional, y que inciden -desde el momento en que se reconocen tribunales con competencia constitucional- en la determinación de las obligaciones de desconocimiento de reglas que en principio son válidas. La falta de soporte institucional de las teorías sustantivas puede así encontrar sustento en el derecho constitucional. Esto es lo que puede denominarse la tentación constitucional de las teorías sustantivas del control institucional ${ }^{34}$.

33 Críticas de esta clase tienden a ser designadas como "irracionalistas". Así, ejemplar, Greco (2013). Pero esto deriva de una confusión. El argumento no es de rendimiento cognitivo de argumentos políticos, sino de simple separación entre esferas políticas y jurídicas.

${ }^{34}$ Interesantemente, la tentación constitucional ha sido (en general correctamente, sobre todo en lo que dice relación con la interpretación legal) criticada recientemente por un abierto partidario del control crítico bajo la tesis de la continuidad -teoría del bien jurídico- como GreCo (2013), pp. 24 y ss., dando cuenta de la tendencia a hacer invocaciones a la constitución para simplemente señalar que "todo [lo que se argumenta] está ahí”. Esa tendencia es especialmente fuerte en nuestra tradición, en donde la pretensión de constituir a la constitución en "fuente material" de la legitimidad del sistema penal a partir de una identificación de "valores" de los que habría que derivar el contenido (i!) y la función del derecho penal, como si la validez y el contenido de las normas legales no derivara de decisiones políticas tomadas a partir de procedimientos formales, puede ser fácilmente identificada. Por razones de espacio no podemos producir aquí la crítica a este acercamiento, aunque su utilización en Chile, por ejemplo por DURÁN (2011), pp. 145 y ss.; el mismo (2017), pp. 276 y ss., debiera ser al menos llamativa: si el contenido de la Constitución determina el contenido del derecho penal, ¿no debiera esto llevar en Chile a mostrar cómo el derecho penal pretende ante todo proteger a la actividad económica frente a la injerencia estatal? Por supuesto no es esto lo que se quiere decir y en cambio se hacen afirmaciones muy generales sobre decisiones por un Estado social de derecho que impregnarían al derecho penal. Pero, más allá de lo vagas que son esas afirmaciones, ¿̨pueden ser ellas vinculadas del todo con la Constitución de 1980? 
La tentación constitucional tiene dos dimensiones. La primera dimensión es de utilización de recursos institucionales, la segunda de fundamentación. El derecho constitucional posterior a la Segunda Guerra Mundial -y en los Estados Unidos su reconstrucción desde el siglo XIX- ha puesto a disposición del sistema acciones cuyo objeto es precisamente controlar el output de la política, esto es, la legislación. Esas acciones tienen como condición de éxito, por cierto, demostrar (en condiciones fijadas con más o menos indeterminación por la regulación positiva de esas mismas acciones) incompatibilidad entre constitución y ley ${ }^{35}$. Pero la indeterminación del derecho constitucional permite abrigar toda clase de teorías en su interior. Éste es también el caso del principio del daño -"de acuerdo a la constitución, la coacción estatal sólo es legítima en la medida en que se oriente a evitar daño ajeno" - e incluso de la teoría del bien jurídico. La teoría en cuestión puede entonces presentarse como expresión de derecho constitucional aplicado y justificar las definiciones de fines que estructuralmente necesita como contenidas en la constitución ${ }^{36}$. Ésta es la función de fundamentación de la invocación al derecho constitucional.

Dos características deben ser destacadas en esta maniobra: ella no altera en nada el punto de partida sustantivo, pero obliga (o debiera obligar) a reconocer que su éxito institucional sólo puede producirse en los márgenes definidos por las acciones constitucionales. Esa restricción no se produce en la determinación de las condiciones de ilegitimidad del objeto de la crítica -sigue siendo lo

35 Así, por ejemplo, el artículo 93 inciso segundo número de la Ley Fundamental Alemana en relación con el $\$ 13$ número 6 y los $\$ \$ 76$ ss. de la BVerfGG sólo exige como condición sustantiva de éxito de la acción la incompatibilidad del derecho federal o estatal con la Ley Fundamental. No es muy distinto lo que dispone, a su vez, el artículo 93 número 7 en relación con el número 6 de la Constitución chilena.

36 A modo de ejemplo, véase la extensa invocación de parte de la dogmática penal alemana (acertadamente rechazada por el Tribunal Constitucional alemán) al derecho constitucional para intentar dar cuenta de la validez de la teoría de la exclusiva protección de bienes jurídicos. Al respecto, véase de Figuereido Dias (2014), p. 204 y ss.; ENGLÄNder (2015), pp. 616 y ss.; Kudlich (2015), pp. 635 y ss.; SCHÜNEMANN (2003), pp. 142 y ss. Críticos Appel (1996), pp. 404 y ss.; BäCKer (2015), pp. 362 y ss.; Gärditz (2010), pp. 331 y ss.; STUCKenderg (2011), pp. 655 y ss.; Vogel (2001), pp. 105 y ss. La crítica tiende a limitarse, sin embargo, a la pura demostración de que la teoría del bien jurídico es inadecuada desde un punto de vista dogmático-constitucional, sin considerar las implicaciones de teoría constitucional y de legitimación intrasistemática que tiene el acercamiento favorecido por la dogmática penal, ni aquellas que a su vez tiene el acercamiento al control constitucional favorecido por la dogmática de los derechos fundamentales conformada por pura aplicación de los métodos de razonamiento y fijaciones anteriores de contenido por parte del BVerfG. Que esto necesariamente conlleva un déficit de potencial de rendimiento cognitivo -necesario para el propio funcionamiento de la dogmática- es argumentado, por ejemplo, por JESTAEDT (2009), pp. 33 y ss. 
mismo-, pero sí tiene lugar porque obliga a asumir que la revisión debe tener lugar bajo ciertos estándares formales definidos por las acciones que ahora se interpretan. Esto puede notarse de modo especialmente nítido en los casos en que penalistas discuten sobre revisión de constitucionalidad de decisiones de criminalización: su única preocupación tiende a ser la determinación sustantiva directa de legitimidad de la decisión en cuestión ${ }^{37}$ y si ella podría haberse expresado en una acción constitucional. Ello transforma a las indeterminadas teorías construidas sobre la tesis de la continuidad en teorías algo más determinadas de éxito del control judicial.

Esta transformación que opera a partir de la tentación constitucional nos permite pasar al siguiente punto: si pretenden ser teorizaciones (imprecisas) de las condiciones de éxito del control judicial de constitucionalidad, las teorías que operan bajo la tesis de la continuidad se encuentran sujetas -además de las críticas internas a ellas- a los problemas que pueden verificarse en el ámbito penal respecto al control judicial sustantivo de constitucionalidad. La crítica se confunde aquí con la crítica a sus rivales, a saber, la dogmática de los derechos fundamentales.

\section{II.4. Excurso: sobre la aceptación de discursos sustantivos de control en la jurisprudencia del Tribunal Constitucional chileno}

Antes de pasar a revisar la situación particular de la dogmática constitucional, puede ser importante insistir sobre la relevancia de la crítica al discurso típicamente penal (y respecto al cual, socioacadémicamente considerado, la academia penal tiene competencia) a raíz de un desarrollo jurisprudencial reciente en Chile. Esta necesidad de insistencia en su relevancia requiere una explicación, ya que tiende a ser así que los discursos de control que provienen de la academia penal no tengan ningún reconocimiento institucional. Después de todo, los discursos en cuestión (exclusiva protección de bienes jurídicos, harm principle específicamente penal) son desarrollados en condiciones socioacadémicas de relativa incompetencia, ya que en la distribución del trabajo en la academia es justamente la comunidad que participa de la discusión sobre el derecho constitucional quien asume competencia en la construcción de discursos de control institucional. Como en los discursos de "limitación del ius puniendi", surgidos de la literatura penal, se trata de máximas

37 Ejemplos elocuentes son Greco (2008), pp. 235 y ss.; Noltenius (2015), pp. 95 y ss.; SCHÜNemann (2003), pp. 141 y ss. 
recibidas desde la tradición del derecho natural racional y de la Ilustración que, en general, han mantenido vigencia en la literatura penal, pero que no tienen rendimiento en el control constitucional ${ }^{38}$; la crítica a estos discursos podría ser el reflejo del otorgamiento de relevancia a un objeto que, en este ámbito, no merece atención.

La cuestión, desafortunadamente, ha dejado de ser así entre nosotros. Desde al menos el año 2017, es posible verificar la generación de una línea de resoluciones del Tribunal Constitucional chileno que, en lo esencial, reproducen la estructura de razonamiento propia de discursos críticos elaborados por las ciencias penales: en ellas, pese a aparentar en ocasiones razonar en base al canon constitucional de proporcionalidad, se tematiza abiertamente la finalidad que debe cumplir la pena (resocialización) y se resuelve en base a ello. Paradigmáticas a este respecto son la sentencia de 19 de diciembre de 2017 en la causa rol No 2983-2017, que declaró inaplicable por inconstitucional el artículo 196 ter de la ley No 18.290 en su versión modificada por la denominada Ley Emilia, y las quince sentencias del 27 de marzo relativa a la ley No 18.216 en su versión modificada por la nueva Ley de Control de Armas, en especial aquellas cuyo voto de mayoría fue redactado por el ministro Nelson Pozo ${ }^{39}$. En todas ellas, luego de una larga reflexión sobre el sentido del ius puniendi y de argumentos no siempre claros, el voto de mayoría básicamente declaró inaplicable las disposiciones que excepcionalmente prevén no aplicar penas sustitutivas por un plazo, y con ello hacer cumplir en cárcel la pena privativa de libertad, por ser contrarias a la finalidad de la pena (resocialización) o vulnerar el principio de ultima ratio.

38 En la jurisprudencia del BVerfG, véase la negativa expresa a hacer uso de la categoría del bien jurídico en BVerfGE 120, 224, además de las completamente vacías descripciones de fines de la pena reseñadas en la nota 22. En el caso de los Estados Unidos, la interpretación expansiva de la Octava Enmienda desde Weems v. United States 217 US 349 (1910) ha permitido plantear la pregunta por fines constitucionalmente lícitos en la criminalización y, ante todo, penalización. Pero, más allá de algunas disidencias y prevenciones, en general la Corte Suprema Federal ha controlado finalidades de la legislación penal con un test especialmente amplio: la legislación debe contribuir de algún modo a conseguir un interés socialmente valioso (véase Gregg v. Georgia 428 US 153, 173 (1976); Coker v. Georgia 433 US 584, 592 (1977); ya antes Weems v. United States 217 US 349, 381 (1910)). En el caso de la Corte Europea de Derechos Humanos, la aceptación abierta de finalidades de la pena ha sido explícita. Véase Vinter v. United Kingdom, Applications Nos. 66069/09, 130/10 and 3896/10, sentencia de 9 de julio de 2013, nm. 111.

39 En particular son quince las sentencias dictadas por el TC a este respecto, a saber, las (i) STC 3062-16; 3095-16; 3109-16; 3120-16; 3134-16; 3135-16, todas redactadas en voto de mayoría por el ministro Pozo y que contienen, entre otras cosas, una prevención del ministro Romero, y (ii) las STC 2995-16; 3053-16; 3177-16;3127-16;3172-16;3173-16;3174-16;3185-16;3187-16, estas últimas redactadas por el ministro Romero con una prevención del ministro Pozo. 
Pese a que por cierto siempre es aventurado atribuirle a esta línea jurisprudencial el carácter de "inédita" en el derecho comparado, ella es al menos llamativa en el contexto de los tribunales constitucionales que cuentan con facultades de revisión "fuerte" de decisiones legislativas y tienden a ser mirados en el derecho constitucional comparado (BVerfG, Corte Suprema de los Estados Unidos, en algún sentido Corte Europea de Derechos Humanos). A la luz de los hallazgos de este artículo, no es difícil entender las razones de esa falta de reconocimiento. Ello debiera asimismo llamar a la preocupación en relación al grado de conciencia de la posición institucional de un tribunal constitucional por parte del TC chileno.

\section{II.5. Discursos críticos como discursos dogmáticos constitucionales}

Si el derecho constitucional es el estándar externo que define el éxito de los discursos críticos -y ello es algo que inevitablemente tiene lugar si se asume que se trata de discursos sobre acciones constitucionales-, entonces la pregunta inmediata que puede plantearse es: ¿por qué no se asumen simplemente los discursos elaborados por la dogmática constitucional? Nosotros sabemos que en el caso del derecho penal ello es así por razones que no son sólo socioacadémicas, sino también a causa de la tesis de la continuidad: ella hace que toda restricción sustantiva al poder crítico traspasado desde la teoría de la pena no parezca justificable. Pero ello no sólo produce el efecto de que los discursos en cuestión sufran de problemas de fundamentación -la constitución parece ser usada como excusa para confirmar un punto de partida predefinido-, sino que se encuentren condenadas al fracaso porque, para decirlo en términos populares, juegan de visita: los discursos crítico-penales tienen que asumir que una dogmática que reconstruye una práctica en funcionamiento -la práctica del derecho del control constitucional- es errada. Esto no tiene perspectivas de éxito, más allá de la incipiente y llamativa línea jurisprudencial del TC chileno. Es decir: deben asumir que la law in action reconstruida por sus rivales es incompatible con el texto de la ley constitucional y ello pese a que sea razonable sospechar que ese texto es utilizado por ellas como excusa.

Más perspectivas de éxito en la construcción de discursos eficaces de control parece tener, por ello, la dogmática constitucional. La sección III pretende argumentar en contra de esta asunción: si bien los discursos surgidos de la dogmática constitucional son relativamente precisos en la fijación de condiciones de éxito del control judicial de decisiones legislativas penales ${ }^{40}$, la experiencia muestra

40 Entre nosotros, véanse sólo las descripciones de Fernández (2010), pp. 52 y ss. 
que se trata de prácticas ineficaces en el control de la política criminal en general y, sobre todo, de decisiones política de criminalización o decriminalización. La crítica que realizaremos a su respecto afecta, por ello, tanto a la dogmática penal como a la dogmática constitucional, porque es una crítica de eficacia y adecuación del control judicial sustantivo en el ámbito del derecho penal y, en particular, respecto de decisiones de criminalización. La crítica asume de hecho una misma dimensión de indiferencia frente a la capacidad de ambos acercamiento de dar cuenta del contenido del derecho constitucional: si son o no verosímiles en este punto es algo que no nos interesa, lo que nos interesa es antes mostrar que el rendimiento que pretende obtenerse de ellas es más bien limitado. Ello produce la paradoja de que dos visiones rivales -a grandes rasgos: teoría del bien jurídico (como ejemplo paradigmático de construcción de la dogmática penal) o dogmática de los derechos constitucionales en el control de la legitimidad sustantiva del derecho penal ${ }^{41}$ - sean expresivas de un mismo punto que es sometido a crítica en la sección, porque su actitud teórica es la misma. Esa paradoja no es más que el resultado de la tentación constitucional: ella produce precisamente que la atención que tiende a entregársele a la constitución por parte de los penalistas funcione en un plano dogmático ingenuo (la pregunta central es: ¿cuándo restringe la constitución el poder punitivo del Estado?) por oposición a un plano teórico y que, por ello, apenas se pregunte por la comprensión de constitución que le subyace y el efecto que ello puede tener en el output de la política. Ésta es exactamente la misma actitud que debe asumir un dogmático del derecho constitucional, pero en ese caso esa pretensión define su actividad.

La sección III pretende, así, criticar el tipo de acercamiento que subyace tanto a los (ingenuos y difícilmente compatibles con el derecho formal vigente y con las prácticas judiciales) principios desarrollados por la dogmática penal como a la dogmática constitucional. El acercamiento que nos interesa revisar asume a este respecto una lógica de regulación y racionalización del uso de la coacción represiva estatal -y, en general, del output de la política- que, en el mejor de los

\footnotetext{
41 Éste es el título de un artículo reciente de Friedrich STUCKEnBerg (2011), criticando los fundamentos de la teoría de los bienes jurídicos. El mismo argumento es expuesto por AppeL (1996); GärdiTZ (2010); el mismo (2017). Contra Gärditz, especialmente enérgicos GreCo (2013); MarTins (2013); el mismo (2015); Noltenius (2015). Para nuestros efectos, esto no es más que una disputa de familia con el mismo pecado de origen: su confianza en el control judicial.
} 
casos, es indiscriminadamente judicial ${ }^{42}$. Su asunción básica debe ser que el modo óptimo de racionalización del ejercicio de la potestad punitiva es la revisión directa y (supuestamente) a-política de su racionalidad -lo que naturalmente debe implicar revisión de contenido-, esto es, alguna clase de control judicial de las leyes. La eficacia de esa asunción es lo que nos interesa criticar en la sección III.

\section{La crítica: ineficacia e inadecuación del control judicial en lo referido especialmente a decisiones de criminalización}

La dogmática constitucional y, en general, la práctica del control judicial no adolecen de los defectos que típicamente se encuentran en la literatura penal sobre el control de la política criminal. La dogmática constitucional no necesita operar sobre una tesis de continuidad sustantiva entre explicación de legitimidad e instituciones particulares bajo atribución fija de fines lícitos ni tiene (a menos que hayan patologías específicas, lo que no nos interesa analizar aquí) problemas de fundamentación en el derecho vigente. Al contrario: se trata de discursos construidos precisamente en relación al derecho vigente y, salvo en casos patológicos, confirmados por la práctica jurídica real. Su falta de problemas de fundamentación no implica, sin embargo, que haya que reconocerles eficacia en la pretensión que les es propia en todo ámbito, incluyendo el ámbito de la legislación penal. Si, como se supone, el control judicial tiende a racionalizar en general el output del sistema político, es algo que su fundamentación en el derecho constitucional no permite responder y que merece ser revisado.

En esta sección nos interesa evaluar esa capacidad de rendimiento. Como veremos, visto desde el punto de vista del resultado final del producto que pretende ser controlado, hay amplios motivos (III.1) para atribuirle al menos falta de eficacia al control judicial: el resultado de la política criminal represiva (el sistema penal en general) ha tendido a verse aquejado de rasgos irracionales. Frente a ello, como veremos, la práctica de control constitucional no sólo se ha mostrado (con razón) reacia a intervenir, sino que la experiencia comparada más relevante de intervención judicial -la actividad de la Corte Warren en los Estados

\footnotetext{
42 Digo aquí "en el mejor de los casos" porque es usual que haya completa ceguera frente a los problemas institucionales vinculados al derecho constitucional; se asume simplemente que una norma que pueda ser considerada lesiva de derechos fundamentales sería inconstitucional, y por lo mismo no válida, sin preguntarse por quién y cómo tiene potestad para declarar esto. En el mejor de los casos, hay al menos conciencia en que la entrega de poder a todos los tribunales o a uno o algunos de ellos para realizar esto, es una decisión crucial en la conformación de un sistema jurídico actual.
} 
Unidos- parece haber contribuido a la producción de ese resultado. Por cierto, ello no quiere decir que el problema le sea imputable a la práctica judicial; son antes las características de la acción política en materia penal aquello que incentiva la producción del resultado en cuestión. Pero, como muestra la sección III.2, es tal vez justamente la incapacidad de asumir esa lógica -claramente perceptible cuando uno analiza las dinámicas de las decisiones de criminalización- aquello que explica la falta de éxito de los mecanismos de control construidos sobre la lógica judicial.

\section{III.1. Ineficacia y carácter contraproducente del control judicial penal}

Comencemos, de este modo, con el diagnóstico relativo a la ineficacia en el control del output de la legislación penal contemporánea: en paralelo al crecimiento exponencial de las potestades de control de los tribunales constitucionales, la política criminal ha tendido a irracionalizarse. Sobre los problemas políticos de la política criminal volveremos más adelante, pero por ahora basta con mencionar las razones de este diagnóstico negativo. El nombre con el que se conoce al fenómeno de irracionalización de la política criminal es (entre otros) "populismo penal” 43 . Para evitar, sin embargo, reconocer en el diagnóstico una pura crítica política vinculada a una comprensión previa de su superación política -sea lo que sea el no populismo penal-, el mejor modo de demostrar que el fenómeno puede ser bien descrito con el concepto de "irracionalidad" es dando cuenta del carácter internamente contradictorio que tiende a exhibir la política criminal contemporánea. Así, la configuración de la persecución penal contemporánea puede caracterizarse, por un lado, por su alta selectividad y asunción de que la criminalidad cotidiana es un hecho que no puede sino ser aceptado -precisamente por eso, el sistema acepta que la gran mayoría de los delitos no sean perseguidos, ni siquiera investigados ${ }^{44}-$, pese a que el discurso político asume la tendencia exactamente opuesta, a saber, una cierta constatación de descuido

\footnotetext{
43 Un nombre alternativo aplicado a la tendencia en cuestión es "politización" del derecho penal. Esta designación es problemática no sólo por sugerir erróneamente un carácter no político del derecho penal, sino ante todo porque aquello que caracteriza al desarrollo reciente de la política criminal no es su inserción en discursos políticos competitivos -a lo que apunta típicamente el concepto de "politización" de algún fenómeno-, sino precisamente el hecho de que todo discurso político se muestre al menos en apariencia comprometido con un programa de seguridad ciudadana similar. Así, Garland (2001), pp. 13 y s.

44 Véase Garland (2001), pp. 10 y ss., especialmente 18 y s. A este respecto, véase también Silva SáncheZ (2006), pp. 74 y ss.
} 
frente al manejo de la criminalidad cotidiana y a la necesidad de reforzarlo. Como discurso y práctica son aquí contradictorios - por un lado acciones constantes de racionalización administrativa de la persecución, por el otro insistencia no sólo comunicativa en la necesidad de persecución de todo delito- y como la mediatización de la delincuencia tiende a revelar esa contradicción, la política criminal asume una tendencia de inflación y deflación constante que no sigue ninguna dinámica racional ${ }^{45}$. Ello es incluso atribuible a sistemas que no han caído en un irracionalismo punitivo extremo reflejado en tasas de encarcelamiento absurdas desde un punto de vista comparativo ${ }^{46}$, sino que también tiene lugar en sistemas que mantienen políticas de graduación, determinación y ejecución de la pena comparativamente moderadas (en lo esencial: países centroeuropeos y nórdicos).

Frente a orientaciones claramente contradictorias de esta clase y frente a lo evidentemente problemático del resultado derivado de esta configuración -sobrecriminalización ${ }^{47}$, exceso de poder de fiscales, encarcelamiento masivo, etc.-, la orientación al control judicial no ha tenido ninguna capacidad de rendimiento en reencauzar a la política criminal. Ello se debe probablemente en parte a la propia lógica de un sistema judicial: los tribunales deben intervenir sólo allí donde haya merito legal y ello al menos limita (con razón) el desarrollo de algo así como un programa completo de control. Pero justamente esa limitación dada por la tenencia

45 Una pequeña advertencia: la descripción anterior asume la existencia de una contradicción, pero no presenta una explicación a este respecto. Ello no quiere decir que asuma algo así como un carácter conspirativo de la tendencia - control a partir del incentivo de la criminalidad y creación de dependencia de la clase política- o alguna otra clase de explicación. Es probable que se trate más bien de una pura dinámica irracional; para nuestros efectos, su constatación es lo relevante.

46 La referencia es obviamente a los Estados Unidos, en donde la tasa de encarcelamiento es alrededor de 10 veces superior a la de otros países desarrollados. De acuerdo al último reporte disponible del U.S. Bureau of Justice Statistics, en el año 2015 la población adulta total sujeta a alguna clase de encarcelamiento era de alrededor de 2.173.800 individuos, mientras que la población adulta sujeta a control punitivo (incluyendo probation y parole) de alrededor de 6.741.000 individuos. Expreso como tasa, ello implica una tasa de encarcelamiento de 670 encarcelados por cada 100 mil habitantes en total y 870 por cada 100 mil adultos, mientras que hay alrededor de 2.710 adultos por cada 100 mil adultos sujetos a control punitivo penal (https://www.bjs.gov/content/pub/pdf/ cpus15.pdf). La cifra del año 2015 no es especialmente alta e incorpora, de hecho, buena parte de los descensos atribuibles a la política de racionalización de Obama. Comparadas con otros países desarrollados con tasas de criminalidad apenas inferiores a las de los Estados Unidos, las cifras son derechamente dantescas: en los países nórdicos las tasas son de alrededor de 50 encarcelados por cada 100 mil habitantes, en países europeo-centrales alrededor de 80 y en otros países europeo-occidentales, excluyendo a Inglaterra y Gales, alrededor de 100 . Por cierto, en otros países anglosajones -ante todo en Nueva Zelanda-, la tendencia a la expansión carcelaria también puede ser observada, aunque de modo más moderado que en los Estados Unidos.

47 A este respecto, más allá del conocido trabajo de HusAK (2008), véase la incisiva exposición sobre la distribución política del poder resultante en STUNTZ (2002), pp. 505 y ss. 
de potestades de intervención definidas por mérito interno constituye un primer problema que puede serle claramente imputable a un sistema cuyos mecanismos de control son judiciales: la intervención puede ser irracional en relación al output global que produce por la dinámica misma de la actividad judicial, incluso en su versión algo deformada en el caso del control constitucional.

El caso paradigmático de los Estados Unidos puede ser ilustrativo para hacer el argumento: pese a que se trata sin dudas del sistema político en que se han producido resultados político-criminales más irracionales, se trata al mismo tiempo de un sistema en el que el control judicial ha operado y ha intervenido en el sistema. Por ello, no sólo es obvio que la intervención ha sido ineficaz en la producción de un resultado global razonable, sino que además es probable que la tendencia al control judicial haya sido contraproducente. Ésta es la forma en que William Stuntz ha leído el hecho llamativo de que el problema de la sobrecriminalización y la massive incarceration en los Estados Unidos haya tenido lugar en paralelo con la actividad de control de la Corte Warren y luego sobre el sistema construido por ésta: la política federal y estatal interpretó las restricciones en cuestión como una tasa que debía pagar para obtener el resultado que quería -a partir de las garantías procesales estrictas establecidas por la Corte, el resultado esperable era que el éxito punitivo de cada persecución disminuyera-, por lo que la reacción natural era aumentar el número de persecuciones posibles si se quería mantener un resultado final similar, terminando en la explosión irracional que se vive actualmente en los Estados Unidos ${ }^{48}$. Es decir, el control político más agresivo (y, en general, loable) que se recuerde en la historia constitucional reciente, produjo (o, menos ambicioso, contribuyó a producir) el peor resultado político-criminal que se recuerde en la historia político-criminal reciente ${ }^{49}$.

\footnotetext{
48 STUNTZ (2006), pp. 781 y ss., 818 y ss. La explicación es ciertamente algo más compleja: la razón por la que el aumento de la criminalización podría producir un aumento en los resultados esperados de condena, no es sólo por el aumento del número de persecuciones penales -ella ha pasado más bien a ser inmanejable, con lo que aumentar el número no cambia el output de condenas-, sino porque concede poder de negociación a los fiscales para forzar a confesarse culpable pese a la enorme amplitud de defensa posible que un imputado tiene. El aumento de delitos que cada imputado comete constrarresta así el efecto del aumento de defensas procedimentales. Así, STUNTZ (2002), pp. 520 y ss.

49 El juicio probablemente requiera ser matizado: junto con la explosión de la cárcel en los Estados Unidos, el otro fenómeno discutido a su respecto es la significativa baja de la criminalidad al menos si se comparan las cifras de los años 80 con los años posteriores en grandes ciudades. Pero a causa del boom económico al que se encuentra vinculado y a medidas de control no penales, trazar un vínculo causal entre ambos es problemático. No es problemático, en cambio, afirmar que el encarcelamiento masivo y la sobre-criminalización son resultados de la política criminal.
} 
Por supuesto, el constitucionalista optimista podría replicar a esto que ello sólo puede tener lugar en caso de que la legislación (o la administración) mantenga competencias de determinación político-criminal que, por otro lado, puedan tender a producir el resultado que le fuera negado ${ }^{50}$. Así, podría sostenerse que si fue del todo posible sobrecompensar la disminución de éxito persecutorio post-Warren y, llegar, por ello a encarcelamiento masivo por medio de sobrecriminalización, ello sería atribuible al menos en parte a la falta de voluntad de los organismos de control constitucional de incidir sobre la legislación penal sustantiva. La reacción debiera ser, entonces, "cerrar esa puerta" que desbordó el sistema. Es de este modo probable que quien tenga un prejuicio optimista respecto a la capacidad de rendimiento del control sustantivo de constitucionalidad replique que, aunque uno asuma que el diagnóstico de Stunz es correcto, ello no haría más que demostrar que el control debió ser más intenso, que debió continuar en el tiempo ${ }^{51}$ y que, ante todo, debiera haberse referido también al contenido de la criminalización -uno de los instrumentos centrales por medio de los cuales el sistema político, ante todo norteamericano, ha pretendido compensar la baja en la eficacia de las persecuciones por medio del aumento de persecuciones ${ }^{52}$.

El argumento en cuestión tiene, por cierto, un núcleo de verdad. Las cortes constitucionales no han manifestado en general voluntad de intervenir en el

50 Entre nosotros, una tendencia de esta clase puede verificarse en FERnÁNDEZ (2014), pp. 187 y ss.

51 Esto no es una trivialidad. En tribunales con clara dependencia de sus decisiones de la tendencia política que representan sus miembros, es improbable que haya continuidad a menos que deje de haber una distribución del poder político entre partidos rivales.

52 El propio StunTz (2002), pp. 587 y ss.; el mismo (2006), pp. 782 y ss. lo sugiere. Su solución es, sin embargo, curiosa, precisamente porque rompe su punto de pártida: realismo en el análisis de los problemas políticos proponiendo soluciones que el propio análisis admite no son realistas. Por referencia al derecho constitucional español, también LOPERA MesA (2010), pp. 125 y ss. LOPERA intenta presentar su defensa de un control exigente de constitucionalidad material -que llegue a estrechar la diferencia entre juicios de validez constitucional y legitimidad política (i!)-a partir de una concepción de la democracia deliberativa: no podría esperarse que el legislador razone en base a argumentos y cumpla con sus cargas de argumentación si no es estrictamente controlado por un Tribunal Constitucional. Más allá del problema de la transferencia de tanto poder político a un tribunal, el argumento desconoce la tendencia a que se produzcan confrontaciones políticas entre tribunales y Parlamento cuando hay controles demasiado estrictos; ellos no tienden a incentivar la democracia deliberativa (la guerra cultural norteamericana después de la Corte Warren y de Roe v. Wade es expresiva de esto), sino incluso a acrecentar el partisanismo. Esto es incluso el caso de un tribunal hábil en mantener su dignidad epistémica a partir de una resistencia a politización visible (¡precisamente por tener conciencia de lo delicada de su posición!) como el BVerfG: su existencia se vio marcada por conflictos con el gobierno de Adenauer. Que el BVerfG haya sido victorioso hasta hoy es, por cierto, muestra de una disciplina política admirable, tanto de los gobiernos federales como del propio BVerfG, pero éste no ha sido el caso en prácticamente ningún otro país del mundo. 
control de la legislación penal sustantiva y, ante todo, en lo relativo a decisiones de criminalización ${ }^{53}$. La reticencia al control sustantivo es así ciertamente criticada por quienes interpretan la constitución como pura limitación sustantiva ${ }^{54}$, pero la pregunta que debiera plantearse quien tenga una verdadera preocupación política por la criminalización y, a partir de ella, por la tendencia a la configuración irracional del sistema, es por qué incluso tribunales liberales y agresivos en el control judicial no tienden a realizar controles sustantivos de corrección de las decisiones de criminalización.

Explicaciones propiamente jurídicas (bajo lógica de acciones judiciales) no son realmente plausibles aquí. Por cierto, la especialmente intensa restraint de la Corte Suprema Federal de los Estados Unidos en el control de decisiones penales sustantivas ha tendido a ser vinculada, en ocasiones, al hecho de que las enmiendas a su Constitución se centren en garantías procedimentales y no contengan un catálogo del tipo que tienen las constituciones europeas modernas. Pero esto ciertamente no era un obstáculo demasiado importante para la Corte Warren ni para las configuraciones que le siguieron: la asunción de un principio amplio de autonomía puede notarse post mortem en uno de los casos emblemáticos de activismo sustantivo constitucional, Roe vs. Wade, y la referencia a la primera, octava y decimocuarta enmienda ciertamente habría sido suficiente para servir de justificación a un control de esta clase. De hecho, también ante un catálogo al que se le atribuye el reconocimiento de un derecho fundamental general a la libertad de acción la situación es similar: el Tribunal Constitucional alemán

\footnotetext{
53 En Estados Unidos, la reticencia se ha extendido a su vez al segundo aspecto relevante del derecho penal sustantivo, a saber, lo que en sentido amplio puede ser denominado reglas de sentencing (cuantificación, determinación y selección de la pena efectivamente aplicable). Así, por ejemplo, en Ewing v. California 538 U.S. 11 (2003) y Lockyer v. Andrade 538 U.S. 63 (2003), la Corte Suprema Federal no declaró inconstitucionales reglas que implicaban la aplicación de privaciones de libertad perpetuas (o similar) por la realización de hurtos bajo el estándar de "three strikes you are out". Es probable que en esta mayor reticencia comparativa influya el grado alto de relevancia política que tiene el tratamiento punitivo propiamente tal en los Estados Unidos.

54 Ilustrativos, Greco (2008), pp. 237 y ss.; SCHÜNEmann (2003), pp. 141 y ss. Un diagnóstico externo lúcido sobre las reacciones de la dogmática penal alemana frente a la negativa del BVerfG de ejercer controles bajo el esquema conceptual del bien jurídico es entregado por DubBer (2011), pp. 88 y ss.: la dogmática penal alemana asume que el problema del control de la política criminal no es político, sino (en palabras probablemente imprecisas en nuestras condiciones actuales de Dubber) "ontológico" y que, precisamente por ello, no se trata de ajuste a condiciones de razonamiento construidas sobre pretensiones de otra clase. El BVerfG no puede, en cambio, sino asumir que se trata de control sobre decisiones políticas. Entre nosotros, y pese a afirmar asumir una posición más bien "procedimentalista" de la Constitución, FERnÁNDEZ (2014), pp. 189 y ss.
} 
también ha tenido una actitud reticente al control sustantivo de decisiones de criminalización durante prácticamente toda su historia, negándose a declarar la inconstitucionalidad de la sodomía consentida entre adultos en 195855; la sodomización consentida de un adolescente en 197356; la producción, tráfico y posesión de canabis en 199457 , y el incesto entre hermanos en $2008^{58}$.

Con ello, las cortes con competencia constitucional ciertamente han tenido a su disposición instrumentos para realizar control judicial. La respuesta a la pregunta por las razones de esta reticencia sólo puede ser, por ello, político-institucional ${ }^{59}$. Éste es el punto en que el segundo argumento relativo a la ineficacia de un sistema de control con lógica judicial pasa a ser comprensible: hay buenas razones para que los tribunales sean reticentes a este control y, de hecho, la intervención puede tender a afectar a las instituciones mismas. El argumento puede, de este modo, ser resumido así: el problema de la réplica a la denuncia de Stuntz por medio del reproche de no extensión a control constitucional de decisiones de criminalización desconoce la naturaleza de las decisiones de esta clase y, con ello, las razones por las que éstas no tienden a ser tomadas. La literatura (ante todo: en la dogmática penal) tiende a proceder aquí por la pura vía de generación de un reproche, sin detenerse a considerar las razones por las que el fenómeno reprochado se produce y que debieran ser útiles para entender el verdadero problema que subyace a la criminalización. Como veremos, ello implica que los tribunales deben ser o bien

55 BVerfGE 6, 389.

56 BVerfGE 36, 41.

57 BVerfGE 90, 145.

58 BVerfGE 120, 224.

59 Esto es incluso reconocido por GreCo (2013), pp. 24 y s. Greco parece operar bajo la premisa de que la ciencia jurídico-penal debiera renunciar a una pretensión de influencia constitucional y, con ello, dejarle el derecho constitucional a los constitucionalistas y a los tribunales constitucionales, porque, a diferencia del derecho penal, el derecho constitucional implica una asunción de una posición de poder que requiere de manejo político responsable. La falta de poder de la ciencia penal permitiría, en cambio, la estructuración de discursos más ambiciosos de control de legitimidad. Que la ciencia penal no debiera "constitucionalizarse" es algo que puede ser concedido a GRECO: la pretensión de que el derecho penal no es más que derecho constitucional aplicado es jurídica y políticamente inaceptable. Pero "ciencia penal" significa aquí dogmática del derecho positivo legal. Cuando se trata, en cambio, de preocupación por la criminalización, la invocación de la falta de poder de la pertenencia académica y, con ello, la posibilidad de articular discursos (supuestamente) más ambiciosos para negarse es más bien expresión de irresponsabilidad política. Entre nosotros, también FERNÁNDEZ (2014), pp. 201 y ss., advierte correctamente que una práctica de control preventivo de constitucionalidad, dada la orientación general del sistema político respecto de la delincuencia, es improbable que se desarrolle. 
patológicamente tímidos (con razón) en el control de decisiones sustantivas, o bien arriesgan quedar ellos mismos, y el sistema general, en peor posición. Para analizar las razones de este diagnóstico y qué quiere decir exactamente nos centraremos específicamente en las decisiones de criminalización en la próxima sección.

\section{III.2. El carácter irreductiblemente ideológico de (ciertas) decisiones de criminalización y el control judicial}

¿Qué es aquello que produce esta tendencia institucional comparada a no intervenir demasiado en el control de decisiones de criminalización? Una pista mucho más plausible que la imputación de falta de fuente o de mala lectura del derecho constitucional vigente puede encontrarse al analizar el resultado que tuvo una decisión como Roe v. Wade: ella tuvo el efecto de confirmar la inserción de la institución misma -la Corte Suprema de los Estados Unidos- en el conflicto que pretendía ser superado, dando lugar a una mucho más intensa politización en sus nombramientos y decisiones, siguiendo la lógica del conflicto en cuestión ${ }^{60}$ y, por lo demás, agudizando el conflicto en torno al aborto en los Estados Unidos. Como veremos, las decisiones de criminalización se relacionan de modo especialmente directo con el conflicto político y, a partir de ello, tienden a asumir una identidad irreductiblemente política -toda pretensión de neutralización por medio de estándares externos tiende a demostrarse inadecuada-. Los tribunales constitucionales se encuentran, por ello, en un dilema: o bien toman una decisión que compromete su propia posición política (por asumir un poder de decisión abiertamente contradictorio con la primacía legislativa), o bien simplemente no interfieren en una práctica político-criminal problemática. Es decir, los tribunales constitucionales se ven obligados a asumir una posición institucional incompatible con la democracia e insostenible en el tiempo -si en algo ha tenido mucha habilidad el Tribunal Constitucional Alemán ha sido en reconocer esto, algo que sus críticos en la dogmática penal no alcanzan a entender-, o bien a ser ineficaces.

Para entender el punto, es crucial observar más de cerca de lo que comúnmente se hace las razones que llevan a la toma de decisiones de criminalización. Construido de modo muy genérico para los efectos de este artículo, uno puede reconocer tres clases de impulsos que se encuentran detrás de las decisiones de

60 Con mayor detalle, Wilenmann (2017), p. 29 y ss. 
criminalización ${ }^{61}$ : un impulso motivado en demandas de reconocimiento de lo que muy ampliamente puede ser denominado un valor; un impulso motivado en demandas de lo que muy ampliamente puede ser denominado un interés sectorial, y un impulso motivado en demandas que pueden ser consideradas "técnicas" o vinculadas a una fuente de conocimiento determinada (ejemplo: demandas de criminalización ligadas a la creencia común compartida de que una sustancia determinada es dañina; demandas de criminalización por diagnóstico compartido de inadecuación de la ley para cubrir casos que debieran estar cubiertos). En general, los tipos de demandas pueden ser vinculados al tipo de actores que se encuentra detrás de ellos: movimientos sociales y grupos de identidad (incluyendo agencias burocráticas vinculadas a la promoción de una identidad determinada) en el primer caso; grupos de interés en el segundo (ante todo gremios económicos, pero también agencias burocráticas definidas en relación con un interés); grupos definidos en relación a un conocimiento específico (comunidades académicas o científicas; en parte, agencias burocráticas definidas por un tiempo de conocimiento). Si bien no todas las demandas que surjan de estas distintas fuentes necesitan confrontarse con una oposición política identificable ni construirse como una pretensión de imposición en un conflicto (no es así, por ejemplo, en el interés de los bancos de facilitar el uso de medios de pago determinados por medio de la criminalización de cuestiones tales como el uso no autorizado de tarjetas o el ciberataque a medios de pago electrónicos), las decisiones de criminalización con relevancia política y respecto de las cuales tiende a solicitarse control judicial sí tienden a estar vinculadas a esta clase de conflictos de valores o intereses. Éste es el diagnóstico que se encuentra detrás de las teorías de la criminalización derivadas del clásico trabajo de Joseph Gusfield ${ }^{62}$ : es ante todo el conflicto político mismo aquello que explica la tendencia a la criminalización.

Especialmente ilustrativas a este respecto son las demandas de criminalización derivadas de pretensiones de reconocimiento de valores y, por ello, simbólica-

$61 \mathrm{El}$ argumento es desarrollado con mayor detalle en WiLEnMAnN (2017), pp. 22 y ss. En lo que sigue, dada la extensión del artículo, prefiero renunciar a exponer de modo más exhaustivo las fuentes del análisis.

62 El estudio clásico de GusField (1986), pp. 4 y ss., sobre la relevancia de la lucha por estatus en las políticas de criminalización se refiere, de hecho, a las políticas de combate al consumo de alcohol en los Estados Unidos de fines del siglo XIX y principios del siglo XX. Véase también BERnARD et al. (2010), capítulo 12; HaGAN (1980); Hopkins (1975); JenNess (2004); SAVELSBERG (1987); TurK (1969); el mismo (1977); Vold (1958), capítulo 11. La cuestión ha sido recientemente retomada por KAHAN (1999), pp. 416 y ss., precisamente para dar cuenta de que el lenguaje con el que tienden a plantearse las discusiones de criminalización (eficacia preventiva, mérito de sanción) cumple una función más bien de sublimación del conflicto real. 
mente orientadas. Éste es el caso originalmente discutido por Gusfield. En las discusiones sobre criminalización que devienen políticamente relevantes, si bien su retórica tiende a asumir una orientación a la "prevención de daño", se trataría ante todo de disputas por atribuciones de estatus o, más generalmente, por el reconocimiento de esquemas de juicio determinados: como la calificación "criminal" coincide con el esquema de juicio empleado para llegar a tal conclusión, la pretensión de criminalización es un modo de pretender confirmación de ese esquema de juicio. La práctica política tiende a manifestar la existencia de pulsiones de esta clase. Esto sucede en distinta medida en varios de los debates centrales de la política criminal contemporánea y que, de hecho, tienden a consumir la energía del sistema político y del control judicial: aborto (el caso tradicional de disputa entre conservadores y liberales); porte de armas de fuego; injurias religiosas o colectivas; posesión y consumo de drogas; crímenes de odio, etc.; en todos estos casos, la pretensión de criminalización tiene por objeto excluir del ámbito de lo políticamente reconocido configuraciones concurrentes de las costumbres sociales antes que prevenir daños ${ }^{63}$. Algo similar puede decirse de la gran área de la criminalidad económica: en ella hay conflicto en relación a la definición como "criminal" (o incluso: en relación a la asociación con lo criminal) de ciertas conductas. La pretensión de criminalización tiene aquí al menos auxiliarmente un rol simbólico, no en el sentido en que generalmente se discute sobre esto en nuestra tradición -como antónimo de eficaz ${ }^{64}$, sino como un modo de enfatizar que la disputa sobre la criminalización en estas áreas se centra ante todo en su significado para la confirmación o rechazo de esquemas de juicio determinados. El origen de la criminalización se encuentra por ello de modo frecuente en una pretensión (latente, casi nunca expresada) de esta clase.

La cuestión es, por cierto, todavía más claramente verificable como conflicto político cuando existen pretensiones de criminalización vinculadas a intereses determinados que son resistidas en base a otra configuración de intereses. Un ejemplo sencillo: la pretensión de castigo por ciertos delitos ambientales implica necesariamente confrontar los intereses de grupos afectados y agentes económicos. No hay aquí algo así como una opción neutra; toda opción está políticamente

63 KaHAN (1999), pp. 418 y ss.

64 Éste es el sentido en el que, conciente de la superposición con el otro sentido de simbólico, por ejemplo, Hassemer (2001), p. 1010, critica la idea de "derecho penal simbólico". 
comprometida, sea cual sea la posición que tenga los mejores argumentos políticos a su favor.

Pese a que a un espíritu liberal la constatación del cumplimiento de esta función por parte de la política criminal seguramente debe producirle rechazo, no sólo no es difícil aceptar el diagnóstico respecto a que en los hechos ello tiene lugar, sino que también la pretensión en cuestión no aparece siempre como ilegítima y muchas veces tiende al consenso político. Éste es el caso, ante todo, cuando se trata de la exclusión de normas que pasan a ser vistas como inaceptables por todos o la gran mayoría de los grupos sociales políticamente representados. Ejemplo: no hay dudas que movimientos de criminalización de ataques homofóbicos o pretensiones de regulación de actividades económicas determinadas pueden ser reconstruidos de este modo -como modos de criminalización de modos de vida concurrentes-, sin que ello sea especialmente problemático. Pero la misma voluntad puede encontrarse en ámbitos que siguen pareciendo problemáticos como el consumo o la posesión de drogas. La patología se da en la tendencia expansiva que tiene esta característica y lo que ella implica: que los subgrupos de una comunidad política buscan, en los hechos, someterse recíprocamente y éste es el aspecto de la política criminal que mayor interés político tiende a generar.

Dada la lógica política de la criminalización, es usual que las demandas de control de las decisiones sean a su vez relativas a las decisiones que son políticamente relevantes (es decir, conflictivas). Y aquí la justicia constitucional puede asumir cualquiera de las dos actitudes que hemos señalado: o timidez congénita (correctamente asumida) u osadía problemática para ella y para la reproducción del conflicto. Esto es: dada la lógica agonal (y, por ello, generalmente no "neutra") de las pretensiones de criminalización, la justicia constitucional tiende a mostrarse ineficaz en su control. La razón de esta ineficacia puede explicarse conceptualmente por razones que son internas a la política: es la política (y no sólo el derecho) aquello que puede convertir toda decisión sobre ella en su propio lenguaje. Si un organismo como un tribunal constitucional puede mantener su poder precisamente neutralizando su propia condición política, necesita no sólo desarrollar lenguajes que neutralicen la sospecha de que actúa políticamente. Más bien, necesita abstenerse en general de poder ser interpretado como actuando por razones políticas. Todavía más: si es consciente de su posición, necesita evitar producir decisiones que tengan el efecto de llamar a reacciones políticas que agudizan el tipo de problema que pretendía resolver. Y esto no puede ser manejado sólo con su lenguaje: un tribunal que asuma un lenguaje no político, pero que incida en exceso en los resultados de la política $-y$, de nuevo, la política va a asumir competencia para 
juzgar esto- seguramente no es creíble. Pero ello lleva o bien a que el organismo en cuestión arriesgue su propio poder $-\mathrm{y}$, en su caso, le sea quitado con razón por medio de modificaciones institucionales-, o bien a que sufra de una timidez que desde fuera no pueda ser percibida sino como patológica ${ }^{65}$.

Para cualquier observador de la realidad del control de constitucionalidad en ámbitos penales, el diagnóstico anterior debiera ser sencillo de aceptar. Por supuesto: en general se reacciona criticando la timidez de los tribunales constitucionales; pero esa timidez tiene causas congénitas y que, por ello, no se dejan superar sin crear el problema inverso. ¿Qué explica, por ello, la fijación con el control judicial sustantivo? En el caso de la dogmática constitucional uno puede imputarle esa fijación a la propia definición de su actividad; sería en ese sentido más difícil explicar el fenómeno en el caso de los académicos a los que les interesa la racionalización del derecho penal y no el manejo de las acciones constitucionales. Pero, en realidad, el origen de su fijación con el control judicial es el mismo: la asunción de un modo de pensamiento dogmático. La relación del derecho penal con el derecho constitucional ciertamente no necesita definirse así, pero la hegemonía de la tesis de la continuidad y la tentación constitucional contribuyen a la adopción de esa actitud. Con ello, su propia asunción originaria de que se trata principalmente de una disciplina sistemática orientada a la determinación de formas de aplicación (al menos intrasistemáticamente) legítimas de sus normas, la convierte en una disciplina con tendencias al razonamiento deductivo estructural y a la conformación de sistemas axiológicos uniformes desde los que se juzga su objeto de análisis ${ }^{66}$. La política ciertamente no se deja juzgar así, por lo que la dogmática la trata a la vez como una amenaza -aunque en ocasiones muy limitadas le sirva para solucionar problemas que ha advertido- y tiende a pensar que la superación de esta amenaza sólo puede tener lugar por medio de juicio. Eso es el control judicial y ello explica que, al menos en nuestro ámbito, siempre sea percibido con insatisfacción.

\section{La alternativa: la constitución como instrumento de encauzamiento de la política}

El diagnóstico anterior relativo a la ineficacia de los discursos de control sustantivos de las decisiones legislativas penales puede ser sintetizado en dos afirmaciones:

65 No puedo insistir demasiado sobre estas dinámicas aquí. Para un análisis acabado, véase WiLENMANN (2017), pp. 24 y ss.

66 Así, también, Luhmann (2013), p. 27. 
(i) el derecho penal es parte de un orden político; (ii) desde el punto de vista de la política, toda pretensión de evaluación sustantiva de legitimidad respecto de cuestiones controversiales puede ser tratada como un discurso político, asumiendo con ello no sólo su carácter problemático respecto de las pretensiones democráticas en una dimensión normativa, sino también el condicionamiento de su eficacia a causa de los equilibrios que organismos no legitimados democráticamente se ven obligados a mantener precisamente por causa de ese carácter problemático.

Lo anterior no implica, sin embargo, desconocer relevancia a toda forma de reflexión sobre las condiciones de legitimidad de la política criminal ni, por derivación, a toda forma de reflexión sobre mecanismos institucionales de encauzamiento racional de ésta, pero sí abandonar la pretensión de que se obtengan resultados relevantes a partir de lo que hemos definido en la primera parte como discursos jurídico-críticos. No es necesario así simplemente conformarse con un desarrollo de la política criminal que se observa asume tendencias irracionales. Más bien, se trata de reconocer que el modo de hacerle frente a esos problemas requiere tener en cuenta el componente político-democrático del problema: el problema es que esa irracionalidad es el resultado de prácticas políticas que son vistas como democráticas. ¿Cómo puede superarse esa tendencia a la irracionalidad sin que ello sea contrademocrático? Ésta es una pregunta que exige pasar del pensamiento dogmático-constitucional (o de la tesis de la continuidad) hacia consideraciones teórico-constitucionales.

\section{IV.1. Teoría constitucional dinámica}

Por teoría constitucional entiendo aquí la observación del modo en que prácticas políticas institucionalizadas configuran un ordenamiento jurídico y de las razones por las que esa configuración tiene lugar, así como la reflexión sobre las condiciones en que ello podría tener lugar de un modo más eficiente. No se trata, en ese sentido, de teoría del derecho o de dogmática constitucional, por un lado, o de teoría política o democrática, por el otro, pese a que la teoría constitucional tenga vínculos con todos estos modos de entender nuestras instituciones.

Frente a la teoría del derecho, una teoría constitucional adecuada asume que el origen político de la conformación del ordenamiento jurídico tiene relevancia en su observación interna. Ello no implica, sin embargo, que la teoría constitucional constituya un discurso que desconozca la lógica propia del derecho y la institucionalización de la política que tiene lugar en éste. Eso la distingue de la pura teoría política y, en parte, de la teoría de la democracia: su pretensión no es 
estudiar la sociología de la política -pese a que ella pueda servirle-, sino el modo en que las prácticas políticas se ven reguladas (constitucionalizadas) con el objeto de permitir la creación de derecho en base a ciertas ideas que le anteceden.

Frente a la dogmática constitucional, ella pretende crear distancia frente a un objeto que, en los términos de la dogmática, debe ser asumido acríticamente como fuente de aplicación judicial: ésta es precisamente la razón por la que las ciencias jurídicas, y ante todo la dogmática constitucional, tratan a la Constitución del modo en que lo hacen. En cambio, al pretender crear conciencia sobre el vínculo entre representaciones políticas generales y las prácticas institucionales que pretenden realizarlas, la teoría constitucional permite ganar distancia frente al riesgo inmanente a la dogmática de irreflexividad externa al sistema que ésta estudia ${ }^{67}$.

$\mathrm{Al}$ desentenderse de la pretensión de disolución de todo lenguaje concurrente sin desconocer la relevancia del análisis intrajurídico, la teoría constitucional puede ser vista como una disciplina de las tensiones: ella asume que el problema central del derecho constitucional y del derecho público en general es la dificultad en la producción de una reconstrucción entre política y derecho sin desconocer el punto de vista de cada una de estas prácticas -esto lo que uno podría denominar la herencia de Weimar ${ }^{68}$-, pese a que por definición no pueda ser un discurso ni puramente jurídico-formal ni puramente político. Se trata, en ese sentido, de un discurso híbrido que se ubica entre lenguajes en principio incompatibles: los lenguajes que asumen la lógica excluyente del derecho (teoría del derecho, dogmática jurídica) y los lenguajes que desconocen la lógica excluyente del derecho (teoría política, teoría de las instituciones, economía institucional, etc.). Ello no quiere decir, sin embargo, que la teoría constitucional no tenga contenido propio y no sea más que una mezcla de discursos independientes. La función autónoma de la teoría de la constitución es dar cuenta del modo en que se conectan los dos momentos que la conforman: se trata así de explicar el modo de funcionamiento interno (es decir, jurídico) de las reglas constitucionales a partir de su carácter posibilitante de prácticas democráticas ${ }^{69}$.

Para los efectos que nos interesan, la constitución debe ser así vista como el conjunto de las reglas cuya función es permitir la creación y el mantenimiento

67 En estos, similar Jestaedt (2009), pp. 26 y ss.

68 Véase Thoma (1930), pp. 6 y ss.

69 Similar SunsteIn (2001), pp. 95 y ss.; WALDRON (2017), pp. 36 y ss. Contra la fijación en la judicialización del control político también Tushnet (1999), capítulos 6-8. 
de un poder político democrático por medio de la (relativa) sustracción de las reglas que definen el ámbito y el modo de ejercicio de la política de aquello que puede ser definido políticamente ${ }^{70}$. Esto es lo central: al sustraer (relativamente) del debate político las reglas que regulan el modo en que la política se orienta a la producción de derecho, ese momento puede ser usado para superar las patologías que en los hechos expresa la política -el peor error que puede cometerse en el análisis constitucional es idealizar la política, entendiendo que en ella hay algo así como un contexto ideal orientado al entendimiento cuando en los hechos no es así- sin incidir en su carácter democrático. Como a nosotros nos interesa además el modo en que se configura una clase de poder sometido a restricciones de fuentes -principio de legalidad- que se confunden con las clases de fuentes sometidas al procedimiento político por antonomasia -el procedimiento de formación de las leyes-, nos interesa revisar cómo pueden ser superadas procedimentalmente las patologías de la política criminal sin que ello afecte su carácter democrático. En una frase: soluciones políticas para problemas políticos.

\section{IV.2. Pesimismo politico criminal: el desafio en relación a algunas de sus patologías}

El diagnóstico anterior sugiere abandonar definitivamente la orientación metodológica tomada de la dogmática y adoptar una "orientación en base a problemas"71 en el ámbito de la investigación sobre racionalización de la política criminal ${ }^{72}$. Si se quiere que el derecho constitucional tenga rendimiento en la racionalización del output de la política criminal, las razones de la desconfianza frente a ésta tienen que ser buscadas en descripciones más precisas de sus patologías.

Para estos efectos no sirven descripciones demasiado generales de los problemas del derecho penal. La desconfianza política que manifiesta la dogmática penal es en este aspecto problemática. No es problemática por el hecho de expresar esa actitud, sino más bien porque las descripciones de la justificación de esa actitud son demasiado gruesas. Puede ser que la violencia estatal, la afectación intensa de derechos fundamentales y descripciones de esta clase puedan justificar preo-

\footnotetext{
70 Véase Depenheuer (2010), Nm. 13 y s.

71 Luhmann (2013), pp. 26 y ss.

72 Ésta es una asunción que se deja generalizar en el ámbito del derecho constitucional democrático: éste puede ser comprendido in toto como una respuesta a problemas de funcionamiento de la democracia. Así, ya Thомa (1930), pp. 5 y ss. Véase también BöCKENFÖRDE (1992), pp. 16 y s.
} 
cupación política con el derecho penal y puede ser que sea importante mantener conciencia sobre ello -la ciencia penal se ha construido, en parte, sobre esa asunción política-. Pero esto es demasiado impreciso para explorar soluciones institucionales, porque todavía no se identifica qué es aquello que es externo a lo que la política quiere usar -el derecho penal- que hace que su uso político sea problemático.

Por supuesto, hay formas obvias de violencia estatal que son incompatibles con la democracia: el asesinato de sus ciudadanos por parte de la policía o la condena por la pertenencia a un grupo de origen determinado no puede ser compatible con ésta. La retórica de la desconfianza frente a la política se nutre de ejemplos de esta clase: jsi no estamos dispuestos a privarle de reconocimiento al poder estatal formalmente ejercido cuando tome acciones de esta clase, aunque las disfrace de derecho penal, entonces no defendemos verdaderamente la democracia! Pero en un Estado que funciona normalmente no son éstas las clases de decisiones que deben ser tomadas - isi el Estado asesina bajo alguna permisión formal como sucedía en la antigua RDA o con impunidad material como en el Chile de la dictadura, entonces seguramente el problema estaba en la conformación del poder político!-, sino decisiones controversiales ${ }^{73}$.

Aunque el catálogo debiera ser ciertamente completado con muchos más diagnósticos de patologías ${ }^{74}$, al menos tres patologías han sido elegidas para trazar el argumento aquí: la posibilidad de instrumentalización política directa del poder del Estado y, en particular, por la administración; el denominado "populismo penal”, y el carácter disruptivo de la propia política que posee el derecho penal. Como veremos, la elección de estas patologías no tiene lugar sólo por su relevancia, sino también porque el modo de reacción institucional respecto de cada una de ellas parece ser distinto.

73 La capacidad de hacer pasar políticamente por acciones dañosas (y por ello susceptibles de criminalización) comportamientos controversiales conforme a normas sociales es algo que tiende a ser criticado a la teoría del bien jurídico: ella más bien incentiva la criminalización, porque entrega un discurso de justificación más bien sencillo. En la literatura en inglés, instructivo sobre el éxito político de iniciativas típicamente "moralistas" (prostitución, juegos de azar, drogas, alcohol) en presentarse a sí misma e imponerse como "modos de evitación de daño", Harcourt (1999), pp. 109 y ss. Véase también Lacey (2009), pp. 938 y ss.

74 Véase, por ejemplo, STUNTZ (2002), pp. 569 y ss.; el mismo (2006), pp. 802 y ss., concentrándose en la comunidad de intereses políticos entre parlamentarios y fiscales en los Estados Unidos. Distribuciones y concentraciones de poder debieran ciertamente estar en el centro de las preocupaciones constitucionales penales. La razón por la que en este artículo no son tematizadas profundamente no se debe a su falta de relevancia, sino a la decisión de centrarse en la tendencia de la literatura penal en el derecho penal sustantivo. 
La primera patología es aquella que tiene sin dudas mayor relevancia, pero ella es tan evidente que su tratamiento institucional es relativamente homogéneo en los sistemas jurídicos contemporáneos. Sobre ello volveremos más adelante. La patología en cuestión puede ser descrita de modo sencillo: considerado de un modo puramente instrumental, la posibilidad de perseguir y excluir rivales políticos por medio de la estigmatización penal y, en el caso extremo, del encarcelamiento (antes también: de la muerte) es sumamente eficiente como modo de mantener el poder sin comprometer abiertamente su legitimidad y, con ello, su verdadera fuente (el reconocimiento). En un Estado no democrático, la resistencia frente al poder preatribuido al monárca o tirano podía así ser contrarrestada por recurso a una configuración antirrebelión del derecho penal. En un Estado democrático, quien detenta el poder en un momento determinado puede buscar excluir o perseguir rivales ya no sólo para evitar resistencia, sino derechamente para evitar una competencia que es condición de base de la democracia. Esta patología puede ser denominada tentación a la instrumentalización directamente política de la potestad punitiva.

La segunda patología se vincula a las razones por las cuales la política criminal contemporánea ha asumido una configuración irracional (el "populismo penal”) 75 . Considerado en términos de racionalidad instrumental, el populismo penal es la expresión del rendimiento instrumental electoral de la inautenticidad políticocriminal. La experiencia política reciente ha mostrado lo efectivo que resulta en términos político-electorales la invocación a la necesidad de criminalizar ciertas

\footnotetext{
75 Un nombre alternativo aplicado a la tendencia en cuestión es "politización" del derecho penal. Esta designación es problemática no sólo por sugerir erróneamente un carácter no político del derecho penal, sino ante todo porque aquello que caracteriza al desarrollo reciente de la política criminal no es su inserción en discursos políticos competitivos -a lo que apunta típicamente el concepto de "politización" de algún fenómeno-, sino precisamente el hecho de que todo discurso político se muestre al menos en apariencia comprometido con un programa de seguridad ciudadana similar. Así, Garland (2001), pp. 13 y ss. El uso del concepto de "politización" sugiere al mismo tiempo que "despolitización" es la única alternativa. Es indudable que ése es el programa que se encuentra detrás de las afirmaciones generales de la dogmática penal en torno a la "expansión" y cuestiones por el estilo. Pero la sugerencia de que la "despolitización" es del todo posible en un sistema democrático, por ejemplo por la vía de ampliar facultades de control judicial, desconoce el efecto de que en los hechos ello tiende a tener politización de los tribunales. Convincente en el caso norteamericano, Tushnet (1999), capítulos 6-7. En el caso de un tribunal como el chileno, en el que las designaciones que dependen del Congreso son hechas bajo apropiación de cupos por los distintos bloques políticos, con lo que lo decisivo en cuestiones controversiales termina siendo el origen de las nominaciones presidenciales y dependientes de la Corte Suprema, la cuestión es todavía más evidente. La misma crítica puede ser producida en relación a sugerencias, como la de Pеттіт (2002), pp. 429 y ss.; el mismo (2004), pp. 54 y ss. Similar, Bellamy (2009), pp. 102 y ss., 116 y ss.
} 
conductas o a endurecer prácticas existentes, pese a que en los hechos se practiquen modos de manejo de la política criminal incompatibles con la creencia en la consistencia del discurso político en cuestión ${ }^{76}$. El populismo penal es así la expresión de la racionalidad instrumental electoral de la falta de autenticidad en lo que se refiere a la política criminal: como hemos visto, los movimientos políticos, sobre todo presionados por casos escandalosos mediáticamente difundidos ${ }^{77}$, tienden a insistir crecientemente en la necesidad de "mayor mano dura", llevando a cabo acciones de criminalización tendientes a mostrar la seriedad de ese discurso, pese a que la práctica real del poder punitivo sea incompatible con ese discurso ${ }^{78}$.

La última patología puede ser vinculada, como hemos visto, a la inevitable inserción de la legislación penal en política de confrontación ideológica y de intereses, pese a su superposición con una retórica política de orientación preventiva. Pese a que esto no es propiamente una "patología", si se trata de una condición concomitante que puede producir efectos patológicos y que, ante todo, lleva a la inserción prácticamente necesaria de toda actividad de control en la lógica de la política.

La combinación de las dos últimas patologías políticas ligadas al derecho penal muestra el nivel de dificultad con el que se topa cualquier pretensión de regular los procesos de conformación de la política criminal: el derecho penal influye en el proceso político tanto por la popularidad de la apelación a la seguridad -pero aquí no tiene, en nuestras condiciones actuales, demasiada capacidad de ser políticamente relevante por el (falso) consenso existente al respecto ${ }^{79}$, sino que su invocación parece ser simple condición necesaria de éxito- como por su valor en la confirmación de normas sociales de relevancia política y, a partir de ello, en la exclusión de normas sociales contradictorias con éstas.

Piénsese por ejemplo en el modo en que podrían influir las discusiones político-criminales en una elección dominada por dos tendencias ideológicas antagónicas. Un ejemplo simple: en la coyuntura política, puede identificarse influencia de discusiones político-criminales en unas elecciones a partir de una discusión ideológica (digamos, para hacer fácilmente comprensible el argumento,

\footnotetext{
76 Véase Garland (1996), pp. 447 y ss., 459 y ss.; el mismo (2001), pp. 13 y ss.; STuntz (2002), pp. 509 y ss. Entre nosotros, matizado, Silva Sánchez (2006), pp. 7 y ss.

77 Реттіт (2002), pp. 429 y ss., analizando lo que denomina la "outrage dynamic" de la política criminal.

78 Similar, LACEY (2009), p. 946 y s. Sobre el trasfondo político de la convergencia en la (inauténtica) mano dura de la izquierda y la derecha, véase ReINer (2010), pp. 256 y ss.

$79 \mathrm{Al}$ respecto, todavía instructivo SiLva Sánchez (2006), pp. 69 y ss.
} 
despenalización de la posesión y del microtráfico de ciertas sustancias frente a mantenimiento o ampliación de ésta) y en relación a una sensación de inseguridad vinculada a criminalidad cotidiana (en Chile) o a terrorismo (en Europa y en los Estados Unidos). En nuestras condiciones actuales, es probable que el segundo tema apenas tenga influencia en la demarcación de posturas -es probable que la gran mayoría de los partidos con representación política relevante propongan alguna clase de mano fuerte, acusando al otro de no serlo o de que aquello que proponen desconoce el núcleo del problema actual de seguridad ciudadana ${ }^{80}$-, mientras que sólo el primero permita demarcar posiciones políticas. Ello asegura la dinámica del desarrollo de la política criminal por una vía tendiente a la irracionalidad: el proceso de inflación y deflación sin dinámica racional de la política criminal "de seguridad" no tiene control político a causa de la racionalidad instrumental de la falta de autenticidad actual ${ }^{81}$ y a su inserción en dinámicas de escandalización, mientras que la política criminal simbólica concentra el ámbito de lo políticamente relevante.

Hay, de este modo, al menos tres preocupaciones centrales de las que hacerse cargo al regular las condiciones de constitución del sistema penal: (i) evitar concentración de facultades ante todo en autoridades con participación política, para contrarrestar el riesgo de instrumentalización; (ii) hacer frente a la tendencia a la irracionalidad de la política criminal a causa de la racionalidad político-electoral que exhibe la inautenticidad; (iii) controlar las pulsiones políticamente autodestructivas que pueden identificarse en el debate político criminal, sabiendo que resulta inverosímil e incluso deseable excluir del todo las pretensiones simbólicas ligadas al derecho penal.

80 Uno podría decir que, en el caso del terrorismo, las posturas políticas sí presentan diferencias relevantes entre sí y que esto es especialmente claro en las elecciones actuales en los Estados Unidos: expulsión y control de ingreso de musulmanes (Trump) vs. trabajo con comunidades musulmanes de modo de reforzar la labor de inteligencia (Clinton). Eso es cierto, pero es importante notar que las diferencias centrales no se encuentran en ámbitos vinculados al derecho penal. Es poco probable que la postura liberal proponga aquí restringir las penas aplicables a delitos terroristas y las enormes facultades de investigación a su respecto. La tendencia a confundir los conceptos de "seguridad ciudadana" (como descripción general de la orientación a la prevención del Estado) y "derecho penal” hace perder de vista esta diferencia, pero ella es políticamente central: muestra cómo precisamente el derecho penal ha perdido capacidad de marcar diferencias políticas más allá de las áreas de relevancia simbólica (lucha por status, en el sentido de Gusfield y Kahan).

81 En Chile, esta afirmación probablemente deba ser matizada: la seguridad ciudadana ciertamente juega un rol central en la política, pero por la vía poco glamorosa de acusaciones recíprocas de ser el responsable por la situación actual y no, en cambio, en base a diferencias sustanciales en la aproximación al tema. 


\section{IV.3. Instrumentos de racionalización constitucional de la política más allá del control judicial sustantivo}

Pese a que este artículo pretende ser ante todo crítico de la eficacia del control judicial y llamar la atención sobre la necesidad de pensar en otros modos de racionalización de la política criminal orientados a la solución de problemas precisos de racionalidad política que puedan ser identificados en este ámbito, es natural que finalice con un pequeño esbozo de mecanismos que puedan producir este resultado. Sin una exposición de esta clase, no es evidente que se entienda lo que se quiere decir con "soluciones políticas a problemas políticos". Sin embargo, antes de exponer sobre estos mecanismos, es importante tener en cuenta que, al igual que en todo problema político, no es obvio que todos estos problemas se dejen resolver con el mismo grado de eficacia por medio de mecanismos institucionales: algunos problemas políticos pueden ser resueltos de modo más o menos decisivo con arreglos institucionales -asumiendo, por cierto, que el poder político general no se degenere-, mientras que otros son tan expresivos de patologías de la política que las tentativas de solución son, por así decir, siempre experimentales. Como veremos, las tres patologías elegidas demuestran ser solucionables institucionalmente en distinta medida.

Para clarificar el punto, podemos ensayar una distinción por medio de dos variables de dos opciones cada una: si el problema político ya es, en algún sentido, solucionado por el derecho constitucional -opciones: sí o no-, y en qué medida las soluciones institucionales pensables permiten solucionar el problema en cuestión -opciones: de modo decisivo o de modo experimental-.

La aplicación de la distinción es relativamente evidente en el caso de la primera patología (riesgo de instrumentalización política directa). El derecho constitucional ya soluciona esta patología de un modo más bien decisivo en las tradiciones constitucionales occidentales por medio de mecanismos conocidos: exigencia de judicialidad de la imposición de la pena, independencia del poder judicial, legalidad e irretroactividad 82 .

En cambio, los problemas ligados al "populismo penal" -el hecho de que la inautenticidad político-criminal sea electoralmente racional y con ello tenga

\footnotetext{
82 Sobre la judicialidad de la imposición de la pena y del control como primera garantía constitucional véase Von ARnauld (2010), Nm. 45 s. Sobre la privación de poder (como potestad) del ejecutivo en buena parte del ejercicio de la potestad punitiva (bajo una implícita prohibición de asunción de ese poder), MölLERS (2008), pp. 52 y s.
} 
realidad política- o a las pulsiones destructivas ligadas al derecho penal no se encuentran tematizados, al menos de modo decisivo, por el derecho constitucional.

En el primer caso, las exigencias de legalidad de la ley y con ello la unión de la política criminal a procedimientos políticos públicos podrían ser vistas como una pretensión experimental de solución del problema en cuestión, pero ellas han demostrado no ser por sí mismas eficientes. A este respecto puede pensarse, sin embargo, en soluciones procedimentales experimentales ulteriores que contribuyan a superar el problema. Una propuesta que tiende a ser escuchada a este respecto es aumentar el quorum de aprobación de leyes penales para evitar el uso político del derecho penal ${ }^{83}$. Pero no sólo es difícil ver en qué sentido la sujeción a estos quorum contribuye a solucionar los problemas en cuestión -recuérdese: el populismo penal opera bajo un acuerdo entre tendencias políticas posibilitada por la racionalidad instrumental de la inautenticidad (más allá de la influencia de los medios, por cierto)-, sino que quienes tenemos experiencia con sistemas que hacen uso de estos mecanismos sabemos que producen muchos más problemas que soluciones ${ }^{84}$. En el caso penal esto también es obvio: las leyes penales existentes se petrificarían por medio de la concesión de poder de veto en su modificación o eliminación a las minorías en caso de que se establecieran quorum calificados. El hecho de que prácticamente todos los controles de constitucionalidad fracasados hayan tenido lugar respecto de leyes penales existentes debiera servir de inmediato para demostrar por qué esto es problemático. Lo mismo puede decirse respecto de las decisiones de criminalización que deben ser tomadas (porque son políticamente defendibles, justas, etc.): si ellas afectan intereses representados políticamente -y es muy probable que lo hagan-, las decisiones no podrían ser tomadas si se establecen quorum calificados.

Más razonable que establecer quorum calificados es, por ello, establecer obligaciones de fundamentación en distintas instancias del proceso legislativo sometidas a estándares especiales de publicidad. Si bien ello tiende a su vez a ser afirmado en la dogmática penal y constitucional, es muy inusual encontrar discusiones en

\footnotetext{
83 Así, por ejemplo, KindHÄUSER (2009), p. 963.

84 Conceptualmente expresado: la sujeción de la política a prácticas de estancamiento produce dos efectos. El primero, dificultar el cambio, sólo puede ser tenido por razonable en caso de que lo existente sea tenido como tal. Correctamente, Bellamy (2009), pp. 113 y ss. Es obvio que en el derecho penal y en la regulación del sistema penal eso no puede ser afirmado en general. El segundo efecto, relevante ante todo en ámbitos de confrontación política, es entregar poder de veto a la eventual minoría que se identifique con el statu quo. Esto es ante todo relevante en ámbitos de confrontación política. El estancamiento aquí sólo puede ser visto como políticamente indeseable.
} 
torno a los mecanismos institucionales que pueden hacer en alguna medida eficaz a la pretensión en cuestión. Pero experiencias y mecanismos políticos de esta clase sí pueden ser encontrados en el derecho comparado. Esto tiene lugar, por ejemplo, en la sección 19 de la Human Rights Act del Reino Unido en relación con proyectos de ley que puedan afectar derechos consagrados en el Tratado Europeo de Derechos Humanos: un ministro debe realizar una declaración de compatibilidad del proyecto de ley con el tratado o dar cuenta de que, pese a que mantenga dudas al respecto, desea continuar por razones determinadas con su tramitación. Pese a que el Parlamento retiene la soberanía no sólo en la determinación del mérito de la compatibilidad, sino, al menos en su interpretación actual, también sobre si la declaración debe hacerse del todo, la práctica tiende a ser deferente ${ }^{85}$. En cualquier caso: el mecanismo asegura que las expectativas de fundamentación se cumplan y que se controlen, ante todo, en base a la mayor difusión pública que la exigencia de la declaración puede implicar. Como sabemos, además, que el problema es la inautenticidad, esas obligaciones de fundamentación podrían ir unidas a obligaciones de considerar consistencia con prácticas pasadas y vigentes. Los tribunales constitucionales pueden tener potestad para controlar esto sin que asuman una dimensión política problemática, siempre que no tengan competencia para juzgar el mérito del argumento, sino simplemente si éste fue expuesto del todo y sometido a debate político auténtico con el grado de publicidad exigido.

También el control judicial ofrece perspectivas de éxito cuando se encuentra unido a condiciones que no impliquen un otorgamiento de poder político de decisión final al tribunal: si éste no es el caso, el tribunal puede a la vez desprenderse de la timidez congénita de tribunales con potestades de control judicial fuerte (para no verse envueltos en su propia constitución en el conflicto político), arriesgando en mucho menor medida politización a causa de ello. Ello sucede en relación con lo que puede denominarse control judicial débil86: la potestad de someter a revisión de un foro judicial la compatibilidad de leyes con ciertos estándares, estableciendo sólo facultades de reenvío al Parlamento para insistencia y fundamentación de decisiones de mantenimiento o modificación que se adviertan problemáticas, sin afectar su validez ${ }^{87}$. Aquí no hay problema con que, además, la

85 Sobre el carácter de condición de validez, o no, de la declaración de compatibilidad, véase Young (2009), pp. 5 ys.

86 Así, también, Waldron (2017), pp. 199 y ss.

87 Éste también es el caso británico bajo la sección 4 de la Human Rights Act de 1998: las cortes superiores pueden realizar declaraciones de incompatibilidad que gatillan procesos de discusión política en casos que 
cuestión pueda operar respecto del derecho penal vigente, estableciendo con ello un mecanismo de revisión del ajuste en la actualidad de la legislación penal -un punto fuertemente criticado al BVerfG, al no declarar la inconstitucionalidad del incesto entre hermanos- ${ }^{88}$.

Por supuesto, nada asegura que estos mecanismos no puedan ser instrumentalizados políticamente, usando así un grupo con representación en el tribunal constitucional a éste como mecanismo de hostigamiento a la mayoría parlamentaria. Ese riesgo sólo puede ser contrarrestado por medio de disciplina razonable en la conformación de los tribunales constitucionales. Pero el riesgo aquí es menor porque el tribunal debe someterse a sí mismo a diálogo con el poder político y, ante todo, porque perdería el poder de decisión final.

Los casos ilustrados sólo se refieren a la cima del problema y, por ello, probablemente a las cuestiones en que el enfoque institucional-procedimental tiene menos posibilidades de contrarrestar decisivamente el problema. Si uno mira, sin embargo, problemas que se vinculan a distribuciones de competencia, el potencial de rendimiento de enfoques institucionales debiera ser de inmediato evidente. Piensése, por ejemplo, en el problema político de la concentración de poder en fiscales (o policías) ligado a las tendencias contradictorias de la política criminal (a grandes rasgos: conjunción de herramientas de selectividad, de negociación y de investigación y vigilancia especialmente amplias). El problema ni siquiera se deja pensar correctamente centrado en el control judicial. Aquí sólo el acercamiento tradicional del derecho constitucional a los checks and balances y distribuciones de poder permite aproximarse al problema.

\section{LISTADO BIBLIOGRÁFICO}

Anscombe, G. E. M. (1963): Intention (Segunda edición, Cambridge/Londres, Harvard University Press).

Appel, Ivo (1996), Verfassung und Strafe (Berlín, Duncker \& Humblot). BÄCKER, Matthias (2015), Kriminalpräventionsrecht (Tubinga, Mohr Siebeck).

\footnotetext{
lleguen a su conocimiento. Caracterizando a partir de ello al sistema constitucional británico como de deliberación política, Young (2009), pp. 10 y ss., 115 y ss. Respecto al caso de Canadá, véase TushneT (2003), pp. 367 y ss.

88 Por una regla de desuetudo penal, STUNTZ (2002), pp. 591 y ss.. La idea de gatillar procedimientos de control vinculados a falta de persecución por delitos determinados puede ser eficiente; la pregunta relevante sigue siendo quién tiene poder de decisión final.
} 
Bauer, Anton (1996a), Die Warnungstheorie (Reimpresión, Goldbach, Keip Verlag).

BAUER, Anton (1996b), Lehrbuch des Strafrechts (Reimpresión, Goldbach, Keip Verlag).

Beling, Ernst (1978), Die Vergeltungsidee und ihre Bedeutung für das Strafrecht (Reimpresión, Aalen, Scientia Verlag).

Bellamy, Rirchard (2009), "The Republic of Reasons: Public Reasoning, Depoliticization and Non-Domination”, en S. Besson \& J. L. Martí (eds.), Legal Republicanism (Oxford/Nueva York, Oxford University Press), pp. 102-120. Bernard, Thomas, Snipes, Jeffrey y Gerould, Alexander (2010), Vold's Theoretical Criminology (6. Edición, Oxford/New York, Oxford University Press).

Binder, Guyona (2002), "Punishment Theory: Moral or Political", en Buffalo Criminal Law Review (vol. 5), pp. 321-372.

BöCKENFÖRDE, Ernst Wolfgang (1992), Staat, Verfassung, Demokratie (2a Edición, Frankfurt am Main, Suhrkamp).

Christensen, Ralph (1989), Was heißt Gesetzesbindung? (Berlín, Duncker \& Humblot).

De Figuereido Dias, Jorge (2014), “Das 'Rechtsgutstrafrecht' als verfassungsrechtliches Prinzip unter dem Blickwinkel der Rechtssprechung des portugiesichen Verfassungsgerichts”, en Goltdammer's Archiv für Strafrecht 2014, pp. 202-219. Depenheuer, Otto (2010), "Funktionen der Verfassung”, en el mismo \& C. Grabenwarter (Eds.), Verfassungstheorie (Tübingen, Mohr Siebeck), pp. 537-568. Dubber, Markus (2011) "Foundations of State Punishment in Modern Liberal Democracies: Towards a Genealogy of American Criminal Law", en R. A. Duff \& S. Green (Eds.), Philosophical Foundations of Criminal Law Oxford/ New York (Oxford University Press), pp. 83-107.

Durán, Mario (2011), "Constitución y legitimación de la pena. Apuntes teleológicos sobre el rol de la Constitución en el sistema penal”, en Politica Criminal (vol. 6 No 11), pp. 142-162.

Durán, Mario (2017), "La prevención general positiva como límite constitucional de la pena. Concepto, ámbitos de aplicación y discusión sobre su función”, en Revista de Derecho (Valdivia) (vol. 29 No 1), pp. 275-295.

Dworkin, Ronald (1986), Law's Empire (Cambridge/Londres, Harvard University Press). 
ENGLÄNDER, Armin (2015), "Revitalisierung der materiellen Rechtsgutslehre durch das Verfassungsrecht? ”, en Zeitschrift für die gesamte Strafrechtswissenschaft (vol. 127 No 3), pp. 616-634.

FERNÁNDEZ, José Ángel (2010), "El juicio constitucional de proporcionalidad de las leyes penales: ¿La legitimación democrática como medio para mitigar su inherente irracionalidad?", en Revista de Derecho Universidad Católica del Norte (vol. 17 No 1), pp. 51-99.

FERnÁndeZ, José Ángel (2014), “Tribunal Constitucional y derecho penal: un estudio crítico", en Estudios Constitucionales (vol. 12 No 2), pp. 187-238.

FEuerbaCh, P. J. A. (1966), Revision der Grundsätze und Grundbegriff des positiven peinlichen Rechts (reimpresión, Aalen, Scientia Verlag).

FEuERBACH, P. J. A. (1986), Lehrbuch des gemeinen in Deutschland gültigen peinlichen Rechts (reimpresión, Aalen, Scientia Verlag).

GärdiTz, Klaus Ferdinand (2010), "Strafbegründung und Demokratieprinzip", en Der Staat (vol. 49 No 3), pp. 331-367.

Gärditz, Klaus Ferdinand (2015), Staat und Strafrechtspflege (Paderborn, Ferdinand Schöningh).

GärdITZ, Klaus Ferdinand (2017), "Demokratizität des Strafrechts und Ultima Ratio-Grundsatz", en JuristenZeitung 2017 (No 13), pp. 641-650.

Garland, David (1996), “The Limits of the Sovereign State. Strategies of Crime Control in Contemporary Society", en The British Journal of Criminology (vol. 36 No 4), pp. 445-471.

Garland, David (2001), The Culture of Control (Oxford/Nueva York, Oxford University Press).

GRECO, Luis (2008), "Was lässt das Bundesverfassungsgericht von der Rechtsgutslehre übrig ?”, en Zeitschrift für die internationale Strafrechtsdogmatik 2008 (No 5), pp. 234-238.

Greco, Luis (2009), Lebendiges und Totes in Feuerbachs Straftheorie (Berlín, Duncker $\&$ Humblot).

Greco, Luis (2013), "Verfassungskonformes oder legitimes Strafrecht? Zu den Grenzen einer verfassungsrechtlichen Orientierung der Strafrechtswissenschaft", en Brunhöber et al. (Eds.), Strafrecht und Verfassung (Baden-Baden: Nomos), pp. 13-36.

Gusfield, Joseph (1986), Symbolic Crusade. Status Politics and the American Temperance Movement (2a Edición, Urbana/Chicago, University of Illinois Press). 
HaGAN, John (1980), “The Legislation of Crime and Delinquency: A Review of Theory, Method, and Research", en Law $\mathbb{S}$ Society Review (vol. 14 No 3), pp. 603-628.

Harcourt, Bernard (1999), "The Collapse of the Harm Principle", en The Journal of Criminal Law and Criminology (vol. 90 No 1), pp. 109-194.

Hassemer, Winfried (2001), "Das Symbolisch am symbolischen Strafrecht", en Schünemann et al. (Eds.), Festschrift für Claus Roxin zum 70. Geburtstag (Múnich, C.H. Beck), pp. 1001-1020.

Hegel, G. W. F. (1986), Grundlinien der Philosophie des Rechts, en Moldenhauer \& Michel (eds.), Werke Band 7 (Frankfurt am Main, Suhrkamp).

Heller, Hermann (1971), Gesammelte Schriften Band I., editado por Drath et al. (Leiden: Sijthoff).

Hopkins, Andrew (1975), “On the Sociology of Criminal Law”, en Social Problems (vol. 22 No 5), pp. 608-619.

HusAK, Douglas (2008), Overcriminalization (Oxford/Nueva York, Oxford University Press).

JaKobS, Günther (1991), Strafrecht Allgemeiner Teil (2a Edición, Berlín/Nueva York, De Gruyter).

JeLLineK, Georg (1908), Die sozialethische Bedeutung von Recht, Unrecht und Strafe (2a Edición, Berlín, Verlag von O. Häring).

JelunneK, Georg (1960), Allgemeine Staatslehre (3a Edición, Darmstadt, Wissenschaftliche Buchgesellschaft).

Jenness, Valerie (2004), "Explaining Criminalization: From Demography and Status Politics to Globalization and Modernization", en Annual Review of Sociology (vol. 30), pp. 147-171.

Jestaedt, Matthias (2009), Die Verfassung hinter der Verfassung (Paderborn, Múnich, Viena, Zürich, Ferdinand Schöningh).

Jestaedt, Matthias (2010), "Verfassungstheorie als Disziplin", en Depenheuer \& C. Grabenwarter (Eds.), Verfassungstheorie (Tubinga, Mohr Siebeck), pp. 3-56. KaHAN, Dan (1999), “The Secret Ambition of Deterrence”, en Harvard Law Review (vol. 113 No 2), pp. 413-500.

KINDHÄUSER, Urs (2009), "Die deutsche Strafrechtsdogmatik zwischen Anpassung und Selbstbehauptung”, en Zeitschrift für die gesamte Strafrechtswissenschaft (vol. 121 No 4), pp. 954-964. 
Kudlich, Hans (2015), "Die Relevanz der Rechtsgutstheorie im modernen Verfassungsstaat", en Zeitschrift für die gesamte Strafrechtswissenschaft (vol. 127 No 3), pp. 635-653.

LACEY, Nicola (2009), "Historicising Criminalisation: Conceptual and Empirical Issues", en The Modern Law Review (vol. 72 No 6), pp. 936-960.

LOPERA Mesa, Gloria (2010), "Posibilidades y límites del principio de proporcionalidad como instrumento de control del legislador penal”, en Mir Puig \& Queralt Jiménez (eds.), Constitución y principios del Derecho penal (Valencia, Tirant lo Blanch) pp. 105-137.

LuHmann, Niklas (1991), Zweckbegriff und Systemrationalität (5a Edición, Frankfurt am Main, Suhrkamp).

Luhmann, Niklas (2013), Kontingenz und Recht (editado por J. Schmidt, Berlín, Suhrkamp).

MacCormick, Neil (1998), "Norms, Institutions and Institutional Facts", en Law and Philosophy (vol. 17 No 3), pp. 301-345.

MaÑalich, Juan Pablo (2015), "Retribucionismo consecuencialista como programa de ideología punitiva. Una defensa de la teoría de la retribución de Ernst Beling", en InDret 2-2015.

Martins, Antonio (2013), "Der Begriff des Interesses und der demokratische Inhalt der personalen Rechtsgutslehre", en Zeitschrift für die gesamte Strafrechtswissenschaft, (vol. 125 No 2), pp. 234-258.

Martins, Antonio (2015), "Die personale Rechtsgutlehre als demokratische Schranke", en Asholt et al. (Eds.), Grundlagen und Grenzen des Strafens (Baden-Baden, Nomos), pp. 79-100.

MarX, Karl (1972), "Über die Todestrafe - Herrn Cobdens Pamphlet", en Karl Marx/Friedrich Engels - Werke, Band 8 (3 $3^{a}$ edición, Berlín, Karl Dietz Verlag), pp. 506-513.

Menke, Christoph (2015), Kritik der Rechte (Berlín, Suhrkamp).

Merkel, Adolf (1892), Vergeltungsidee und Zweckgedanke im Strafrecht (Estrasburgo, Verlag von Karl J. Trübner).

MeYER, Georg, \& Anschütz, Gerhard (2005), Lehrbuch des deutschen Staatsrechts (3a Edición, Berlín, Duncker \& Humblot).

Mir Puig, Santiago (2006), Estado, penal y delito (Montevideo/Buenos Aires, BdeF).

Möllers, Christoph (2008), Die drei Gewalten (Weilerswist, Velbrück Wissenschaft). 
Murphy, Jeffrie (1987), "Does Kant Have a Theory of Punishment?”, en Columbia Law Review (vol. 87 № 3), pp. 509-532.

Noltenius, Bettina (2015), "Strafbegründung und der Grundsatz der Verhältnismäßigkeit”, en Jaeckel et al. (eds.), Grundrechtspolitik und Rechtswissenschaft (Tubinga, Mohr Siebeck), pp. 93-103.

PAWLIK, Michael (2010), "Staatlicher Strafanspruch und Strafzwecke", en Schumann (ed.), Das strafende Gesetz im sozialen Rechtsstaat (Berlín/Nueva York, De Gruyter), pp. 59-93.

Petтiт, Philip (2002), "Is Criminal Justice Politically Feasible?”, en Buffalo Criminal Law Review (vol. 5 No 2), pp. 427-450.

Peтtiт, Philip (2004), “Depoliticizing Democracy”, en Ratio Juris (vol. 17 No 1), pp. 52-65.

Ramsay, Peter (2006), “The Responsible Subject as Citizen: Criminal Law, Democracy and the Welfare State" en The Modern Law Review (vol. 69 No 1), pp. 29-58.

Ramsay, Peter (2014), “The Dialogic Community at Dusk" en Critical Analysis of Law (vol. 1 No 2), pp. 316-332.

ReIner, Robert (2010), "Citizenship, Crime, Criminalization: Marshaling a Social Democratic Perspective" en New Criminal Law Review (vol. 13 No 2), pp. 241-261.

Roxin, Claus (2006), Strafrecht Allgemeiner Teil. Band I (4a Edición, Múnich, C.H. Beck).

SAVELSBERG, Joachim (1987), "The Making of Criminal Law Norms in Welfare States: Economic Crime in West Germany", en Law $\$$ Society Review (vol. 21 No 4), pp. 529-562.

Schmidt, Richard (1895), Die Aufgaben der Strafrechtspflege (Leipzig, Duncker $\&$ Humblot).

SCHMIDT, Richard (1923), Einführung in die Rechtswissenschaft (2a Edición, Leipzig, Felix Meiner).

Schünemann, Bernd (2003), "Das Rechtsgüterschutzprinzip als Fluchtpunkt der verfassungsrechtlichen Grenzen der Straftatbestände und ihrer Interpretation”, en Hefendehl et al. (eds.), Die Rechtsgutstheorie (Baden-Baden, Nomos), pp. 133-154.

SeArle, John (1979), Expression and Meaning (Cambridge, Cambridge University Press). 
Silva Sánchez, Jesús María (2006), La expansión del derecho penal (2a Edición, Montevideo/Buenos Aires, BdeF).

STUCKENBERG, Carl-Friedrich (2011), "Grundrechtsdogmatik statt Rechtsgutlehre. Bemerkungen zum Verhältnis von Strafe und Staat”, en Goltdammer's Archiv für Strafrecht 2011, pp. 653-661.

Stuntz, William (2002), “The Pathological Politics of Criminal Law”, en Michigan Law Review (vol. 100), pp. 505-600.

STunTz, William (2006), "The Political Constitution of Criminal Justice", en Harvard Law Review (vol. 119 No 3), pp. 780-851.

SunsteIn, Cass (2001), Designing Democracy. What Constitutions Do (Oxford/ Nueva York, Oxford University Press).

Thoma, Richard (1930), "Einleitung", en Anschütz y Thoma (eds.), Handbuch des Deutschen Staatsrechts. Band I (Tübingen: Mohr Siebeck), pp. 1-13.

Turk, Austin (1969), Criminality and Legal Order, Chicago, Rand McNally.

Turk, Austin (1977), "Class, Conflict, and Criminalization", Sociological Focus (vol. 10 No 1), pp. 209-220.

Tushnet, Mark (1999), Taking the Constitution Away from the Courts (Princeton, Princeton University Press).

Tushnet, Mark (2003), "Forms of Judicial Review as Expressions of Constitutional Patriotism" en Law and Philosophy (vol. 22 No 3), pp. 353-379.

Vogel, Joachim (2001), "Strafgesetzgebung und Strafrechtswissenschaft - Überlegungen zu einer diskurstheoretischen Strafgesetzgebungslehre", en Schünemann et al. (Eds.), Festschrift für Claus Roxin zum 70. Geburtstag (Múnich, C.H. Beck), pp. 105-118.

Vold, George (1958), Theoretical Criminology (Nueva York, Oxford University Press).

Von Arnauld, Andreas (2010), "Rechtsstaat", en Depenheuer y Grabenwarter (Eds.), Verfassungstheorie (Tubinga, Mohr Siebeck), pp. 703-742.

VON Grolman, Karl (1996), Grundsätze der Criminalrechtswissenschaft (reimpresión, Goldbach, Keip Verlag).

Von Mohl, Robert (1866), Die Polizei-Wissenschaft nach den Grundsätzen des Rechtsstaates. Dritter Band: System der Präventiv-Justiz (3a Edición, Tubinga, Verlag der H. Laupp'schen Buchhandlung).

Waldron, Jeremy (2017), Political political theory (Cambridge/Londres, Harvard University Press). 
Wilenmann, Javier (2017), "Institutional response to criminalization decisions", en International Journal of Law, Crime and Justice (vol. 49), pp. 22-34.

WischmeYer, Thomas (2015), Zwecke im Recht des Verfassungsstaates (Tubinga, Mohr Siebeck).

Young, Alison (2009), Parliamentary Sovereignty and the Human Rights Act (Oxford/Portland, Hart Publishing). 